University of Rhode Island

DigitalCommons@URI

Open Access Dissertations

2007

\title{
Marijuana Abuse in Incarcerated Adolescents: Reasons for Use and Implications for Treatment
}

Rebecca Lebeau

University of Rhode Island

Follow this and additional works at: https://digitalcommons.uri.edu/oa_diss

\section{Recommended Citation}

Lebeau, Rebecca, "Marijuana Abuse in Incarcerated Adolescents: Reasons for Use and Implications for Treatment" (2007). Open Access Dissertations. Paper 921.

https://digitalcommons.uri.edu/oa_diss/921

This Dissertation is brought to you for free and open access by DigitalCommons@URI. It has been accepted for inclusion in Open Access Dissertations by an authorized administrator of DigitalCommons@URI. For more information, please contact digitalcommons-group@uri.edu. 
MARIJUANA ABUSE IN INCARCERATED ADOLESCENTS:

REASONS FOR USE AND IMPLICATIONS FOR TREATMENT

BY

REBECCA LEBEAU, M.P.H.

A DISSERTATION SUBMITTED IN PARTIAL FULLFILLMENT OF THE REQUIREMENTS FOR THE DEGREE OF

DOCTOR OF PHILOSOPHY

IN

PSYCHOLOGY 
Abstract

Research is needed to better understand marijuana use and effective treatment among the incarcerated adolescent population. Preliminary pilot work in detention indicates that a substantial number ( $83 \%$ ) of adolescents are reporting daily marijuana use (Stein et al., 2006). This research attempted to gain a better understanding of the reasons for marijuana use among incarcerated adolescents. The design and intent of this study was to extend basic knowledge of the reasons for marijuana use, establish factors related to marijuana use, and examine if relaxation therapy reduces marijuana use in those who use marijuana as a way to regulate emotions.

Participants were 189 incarcerated adolescents age 14-19 ( $\underline{\mathrm{M}}=17$ years). Participants adjudicated between January 2001 and September 2005 were included in the study if they reported marijuana use prior to their incarceration. Of the 189 participants, $86 \%$ were boys, $32.8 \%$ White, $29.1 \%$ Hispanic/Latino, $28 \%$ African American, and $10.1 \%$ other.

Analyses included a principal components analysis (PCA) to investigate variables that correlate to explain reasons for marijuana use. The PCA did not reveal separate factors for marijuana use. In order to continue testing the hypotheses for the study, items from the Brief Situational Confidence Questionnaire-Marijuana (BSCQ-M) were calculated to form a negative affect and a positive affect variable. Although most of the analyses did not confirm the hypotheses, a few interesting and significant findings were revealed. Results indicated that incarcerated adolescents who were in the negative affect group report higher averages of weekly marijuana 
use and a higher number of days using marijuana at 3-month follow-up than did those who were not in the negative affect group. While those in the positive affect group also reported significant days of use in the past 3-months, there was no difference in the average number of "joints" smoked per week in the past 3 months. Additionally, gender differences were found with females (vs. males) reporting a more significant family history of drug use and were more likely to report that they perceive that marijuana has bad effects on a person.

Further research is needed to examine the reasons for marijuana use among incarcerated adolescents to inform and streamline treatment needs. In addition ethnicity and gender should be included in further investigations into the motivations, quantity, and frequency of marijuana use. These findings can assist in the development and implementation of future marijuana treatment efforts with incarcerated adolescents. 


\section{Acknowledgements}

First, I'd like to thank my major professor Kat Quina for believing that I could actually do this even when I had begun to lose faith. Kat's positive energy and constant support were instrumental to my progress I can not thank her enough.

I also want to thank Lyn Stein, my accidental mentor, a job that seemed to land in her lap whether she wanted it or not. Lyn gave me opportunities to learn and discover in this field that have been invaluable. For this and so much more I thank her.

I am also grateful to my amazing committee members, who have been patient and encouraging through this process; Ginette Ferszt; Ellen FlannerySchroeder, John Stevenson and Jerome Adams.

I want to send a special thank you to the Rhode Island Training School (RITS), in particular Warren Hurlbut, the superintendent of the facility who is dedicated to supporting research projects that will enhance treatment for juvenile detainees; Charles Golumbeske; Louis Como; and the administrative, school, and correctional staff without whom the project could not have been completed. I would also like to thank the RITS detainees for their participation over the years.

Last but not least, a great big, heartfelt thank you to my family for unwavering support from the beginning of this long, difficult journey. They are the reason that $I$ had the courage to even try. I am blessed with a supportive family, friends, and colleagues, all of whom have helped me to keep pushing and to stay positive. From the bottom of my heart, thank you all! 


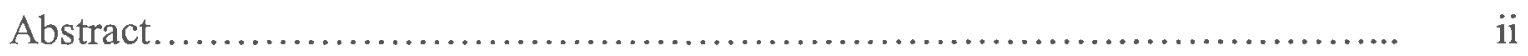

Acknowledgements...................................................... iv

Table of Contents........................................................

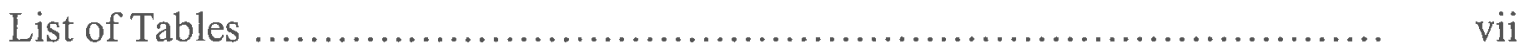

List of Figures.......................................................... viii

Introduction................................................................. 1

Marijuana Use Among Incarcerated Adolescents.......................... 2

Research Examining Variables Related to Adolescent Marijuana Use........ 4

Treating Incarcerated Marijuana Users.................................. 8

Rationale for Current Study and Significance

Potential Implications of this Research.......................................... 13

Current Study

Hypotheses................................................... 14

Method

Participants...................................................... 15

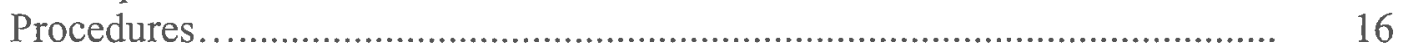

Treatment Conditions....................................... 17

Motivational Intervention...................................... 17

Relaxation Therapy .......................................... 18

Follow-up................................................ 18

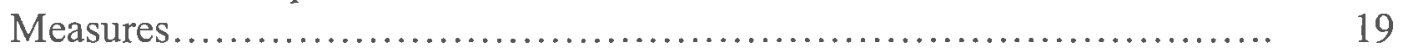

Background Questionnaire.................................. 19

Brief Situational Confidence Questionnaire-Marijuana............. 19

Center for Epidemiological Studies Depression Scale............... $\quad 20$

Marijuana Effects Expectancies Questionnaire................... 21

Substance Use Diagnosis for Marijuana........................... 22

Time-Line Followback-Marijuana.............................. 22

Data Analyses

Phase 1: Preliminary Data Analyses................................... 23

Phase 2: Data Analyses Addressing Dissertation Hypotheses.............. 23

Results...................................................................... 25 
Discussion......

Appendix A: Consent forms.............................................. 41

Appendix B: Measures.................................................. 50

Bibliography.................................................................. 64 


\section{List of Tables}

Table 1: Project Flow Chart....................................... 35

Table 2: PCA 1-Factor Solution........................................ 36

Table 3: PCA 2-Factor Solution.......................................... 37

Table 4: Distribution of Negative Affect Calculated Variable............... 37 


\section{List of Figures}

Figure 1: CESD by Negative Affect (yes/no) ......................... 38

Figure 2: Average Number of Joints per week in the past 3months by Negative Affect (yes/no)......................... 39

Figure 3: Number of Days Smoked Marijuana in the past 3months by Negative Affect (yes/no)

Figure 4: Number of Days Smoked Marijuana in the past 3months by Positive Affect (yes/no).

Figure 5: Average Number of Joints per week in the past 3months by Positive Affect (yes/no). 


\section{Introduction}

Currently marijuana is the most widely used illicit drug in the country (Johnston, O’Malley, \& Bachman, 2003). The 2001 National Household Survey on Drug Abuse (NHSDA) estimated that 37\% of Americans (83 million) aged 12 and older have tried marijuana at least once in their lifetime (Office of Applied Studies, 2001). The Monitoring the Future study (Johnston, O’Malley, \& Bachman, 2003) also reported high rates of marijuana use among middle and high school students across the nation. The NHSDA survey demonstrated that $18 \%$ of 8 th-graders reported having tried marijuana at least once; and by 10 th grade, $17 \%$ reported being "current" users (defined as having used at least once within the past month; Johnston, Bachman, O'Malley, \& Shulenberg, 2001). Among 12th-graders, 46\% had tried marijuana at least once, and roughly $21 \%$ were current users.

Retrospective adult research has shown that $90 \%$ of the adults with marijuana dependence in the United States began using before the age of 18 , half of whom began using before age 15 (Dennis, Titus, Diamond, Donaldson, Godley, Tims, et al., 2002). Moreover, in the past decade, increasing numbers of children under the age of 15 began to experiment with marijuana, illustrating a trend in earlier age of first time use (Dennis, et al., 2002). Treatment admissions for marijuana follow a similar trend, such that those aged 20 and younger account for half of all these admissions in the United States (SAMSHA, 2001).

The negative effects of marijuana use and misuse among adolescents have also increased. Adolescent marijuana users in treatment show an association between higher rates of marijuana use and higher rates of mental disorders (Arseneault, Moffitt, Caspi, 
Taylor, \& Silva, 2000), health problems (Hall, Johnston, \& Donnelly, 1999), and arrests (Webb, Burelson, \& Ungemack, 2002). In fact, most adolescents seeking treatment are mandated through the criminal justice system, arrests ranged from possession of an illegal substance, property, and violent offenses (Dennis, et al., 2002). Researchers have noted that adolescents who use marijuana frequently are more likely to have conduct disorder problems and participate in illegal activites than adolescents who do not use marijuana (Farrell, Danish, \& Howard, 1992; Rob, Reynolds, \& Finlayson, 1990). In the following section the literature on marijuana use among incarcerated adolescents will be reviewed.

\section{Marijuana Use Among Incarcerated Adolescents}

Research assessing marijuana use among incarcerated adolescents is scarce, and the research that has been conducted is somewhat limited in scope by its reliance on the small sample sizes available within the juvenile justice system. The studies investigating basic prevalence data from convenience samples have demonstrated that marijuana use rates are higher among incarcerated adolescents when compared to adolescents in the general population (Dryfoos, 1990). Additionally, prevalence studies have reported that between $50 \%(\mathrm{n}=91)$ and $97 \%(\mathrm{n}=178)$ of incarcerated adolescents used marijuana within the six months prior to their current incarceration (Farrow \& French, 1986; Lebeau-Craven, Stein, Barnett, Colby, Smith, \& Canto, 2000). Thus, it is not surprising that McManus (1984), in a study of 71 incarcerated male adolescents, found that $44 \%$ not only used marijuana daily but had a diagnosis of marijuana abuse.

The high rate of use among adolescents in the juvenile justice system precipitated a change in the climate of juvenile justice in terms of its attitude toward 
identifying substance abusers. This change required drug testing of juvenile offenders, even when the arrest was not a drug-related crime. In 1999, the National Institute of Justice's Arrestee Drug Abuse Monitoring Program (ADAM), previously acknowledged for collecting data among adult correctional samples, collected data on juvenile arrestees. Nine sites found that marijuana was the most commonly used drug among incarcerated adolescents. On average, $53 \%$ of juvenile male and $38 \%$ of juvenile female arrestees tested positive for marijuana.

Juvenile drug testing has become a priority in American correctional facilities in the 1990's when the United States Department of Justice and Drug Enforcement waged its 'war on drugs.' As a result, in the later half of the 1990's, the rate of drug tests among this population doubled (Bureau of Justice Statistics, 1999). With more juvenile detainees testing positive for marijuana use, drug enforcement among this population increased, as did the demand for treatment (SAMSHA, 2001; Webb, et al., 2002). Increasingly, adolescents are court ordered to substance abuse treatment while incarcerated, or are court ordered to in-patient treatment in lieu of incarceration (Webb, et al., 2002).

There is an increased need for assessing marijuana use among this population because the reasons for initiating and continuing use are still unclear. This study will explore factors (e.g., family history, peer history, reason for use) that relate to marijuana use among incarcerated adolescents and attempt to gain a better understanding of the reasons for marijuana use among this population in order to better inform treatment efforts. 
Research Examining Variables Related to Adolescent Marijuana Use

A number of variables have been implicated as risk factors that influence initial marijuana use among adolescents (Bailey \& Hubbard, 1990). These risk factors include having a family history of substance use, peer influence, age of first use, expectancies of marijuana use, and situations in which teens anticipate difficulty in not using marijuana.

Two of the most widely recognized risk factors are family history/parental use and peer influences due to the exposure to others' attitudes toward marijuana use, substance use behaviors in their environment, and reinforcements and punishments for their marijuana use (Bailey \& Hubbard, 1990). There are specific examples within the framework of a family history including parenting styles (reinforcements and punishments), parental discord, negative communication, lack of closeness and family violence factors that have been shown to be associated with initiation of marijuana use among younger adolescents (Carvalho, Pinsky, DeSouza, \& Silva, 1995; Isohanni, Moilanen, \& Rantakallio, 1991; Stoker \& Swadi, 1990, Swadi, 1994). Wills and Cleary (1996) reviewed risk factors for marijuana use and suggested that lower parental support and more parental substance use are strong indicators of initiation as well as the continued use of marijuana among adolescents. Similarly, adolescents with marijuana using peers are more likely to use marijuana themselves, since peer approval is an important factor during adolescence. In fact, peer influence is often labeled as having the largest impact on adolescent substance using behavior (Swadi, 1992). Drug use may serve a social purpose for adolescents as well as providing a setting that is socially acceptable and favorable to drug users. Moreover, Chassin, Curran, Hussong, and 
Colder (1996) found that adolescents with drug using peers have a much faster trajectory toward abusing substances than adolescents who do not have drug using peers.

Age of onset has also been shown to be a risk factor for long term marijuana use. Babor, et al. (2002) investigated subtypes for classifying adolescent marijuana users who presented for marijuana treatment at a number of in-patient and out-patient facilities. Six hundred adolescents ( $82.2 \%$ of them males) participated in the study. Among the 600 adolescents, $85 \%$ reported initiating marijuana use before the age of 15 , with $15 \%$ initiating use at age 15 or older. Age of initiation, above all other variables, yielded unique variance when examining variables that classify those who are marijuana abusers or are dependent on marijuana. Age of initiation has also been shown to be a strong predictor of escalated use and long term abuse and consequences (Kaplan, Martin, \& Robbins, 1986; Swadi, 1999).

In addition, sexual abuse has been positively correlated with subsequent substance abuse (Bulik, Prescott, \& Kendler, 2001; Dube, Felitti, Dong, Chapman, Giles, \& Anda, 2003; Holmes, 1997; Johnson, Ross, Taylor, Williams, Carvajal, \& Peters, 2005; Kendler, Bulik, Silberg, Hettema, Myers, \& Prescott, 2000). Studies have demonstrated that even when controlling for family and peer factors, sexual abuse history is a significant predictor of marijuana, as well as other drug use (Bulik, et al., 2001). Much of the research in this area focuses on childhood victimization, defined as mental abuse, physical abuse, and sexual abuse. Sexual abuse is generally categorized in terms of severity (i.e., inappropriate sexual talk, touching, or penetration). Researchers have concluded that the risk of later substance use increases monotonically 
based on the severity of abuse (i.e., as the severity of abuse increases so does the severity of substance abuse) (Dube, et al., 2003; Ferguson, et al., 1996; Fondacaro \& Holt, 1999; Johnson, et al., 2005; Kendler, et al., 2000). As a caveat, having a parent or parents who abuse drugs is not only a risk factor for marijuana abuse, but is also a risk factor for childhood sexual abuse (Simpson \& Miller, 2002). Thus, when there is a history of sexual abuse, determining causality between drug abusing parents and adolescent marijuana use is extremely difficult. Taken together, both parental history of drug abuse and sexual abuse may substantially increase the risk of later drug use.

The association between sexual abuse history and substance abuse in an incarcerated population was demonstrated by Harlow (1999), utilizing data from the Bureau of Justice Statistics. Additionally, Harlow conducted personal interviews with incarcerated adult males and females. Results indicated that past sexual abuse was not only associated with substance abuse but with violent crime as well. The data confirmed that those who reported sexual abuse in childhood were more likely to use a number of different drugs at a more frequent rate than those who did not report sexual abuse. In 2005, given the limited research in this area, Johnson et al. attempted to replicate Harlow's work with an incarcerated population in a neighboring state run jail. One hundred male inmates were recruited (mean age of 34 years) and data were collected that included sexual abuse history and alcohol and drug use: The relationship between childhood sexual abuse and drug use was examined using the Fisher's exact test. Results were consistent with those of Harlow in that there was a clear association between childhood sexual abuse and later drug use $(\mathfrak{p}<.05)$. Interestingly, when examining each drug separately, among the drugs related to childhood sexual abuse, 
marijuana was the drug used most frequently $(\mathrm{p}<.04)$. Although it may not be possible to find a causal link between childhood sexual abuse and marijuana use, this research will add to the scarce literature examining sexual abuse history and marijuana use in an incarcerated population.

Along with specific background variables a number of researchers have also discussed different attitudes, intentions of use, and behavior as playing distinct roles in the initiation of marijuana use in adolescents (Bailey et al., 1990; Comeau, Stewart, \& Loba, 2001; O'Callaghan \& Hannon, 2003). For example, Gorman and Derzon (2002) analyzed data from a meta-analytic archive of prospective longitudinal studies (40 studies; $\mathrm{N}=3206$ ). The researchers used the data to examine marijuana use in relation to three behavioral traits. These included negative affect (defined as depression, anxiety and self-derogation, emotionality (defined as a susceptibility to becoming easily and intensely distressed), and unconventionality (the propensity toward standards of behavior that are not seen as prevailing values or behaviors of general society, such as drug use). A strong association was found between unconventionality and marijuana abuse $(\underline{\mathrm{M}}=.332)$ and between emotionality and marijuana abuse $(\underline{\mathrm{M}}=.337)$. Babor, et al. (2002) found that low self-esteem, sadness and depression were associated with adolescent marijuana use. Similarly, self-efficacy, defined as a belief in ones abilities to function in a number of different situations, has been found to be correlated with an increase in marijuana use in that those who have low self-efficacy report more marijuana use and more difficulty quitting than those who have high self-efficacy (Stephens, Wertz, \& Roffman, 2004). Loeber, Stouthamer-Loeber, and White (1999) examined longitudinal data on boys aged 7-18 for the co-occurrence of persistent 
substance use with other problem behaviors $(n=1500)$. Logistic regressions showed that mood dysregulation (defined as depressive mood and anxiety) may lead to substance use as self medication. The hypothesis of using substances for the purpose of selfmedicating has been advocated by a number of authors (Aharonvich, Nguyen, \& Nunes, 2001; Green, Kavanagh, \& Young, 2004; Khantzian; 1997, Loeber et al., 1999; Mueser, Drake, \& Wallech, 1998). In fact, Chassin, Pillow, Curran, Molina, and Barrera (1993) claim that there is evidence that affective states (i.e., negative emotions) may have a general, yet important, role in substance use.

Additionally, life events have been recognized as playing a role in emotional states of adolescents and subsequent substance use. Some examples of life events that may increase the risk for using substances includes unwanted pregnancy, high rates of bereavement, and sexual victimization (Brook, et al., 1998; Hernandez, 1992, Swadi, et al, 1999).

Understanding the role of marijuana for adolescents (e.g., smoking marijuana to relieve depressive symptoms) and the risk factors that relate to initial and continued use will potentially enhance treatment efforts among this population. As stated previously, family and peer history of use, age of onset, and other personal expectancy variables, and life experiences have been established as risk factors.

\section{Treating Incarcerated Marijuana Users}

Ever since Martinsen (1974) asserted that any treatment, even at its best, could not deter the behavior of a criminal, there has been reluctance among practitioners, researchers, and policy makers to treat incarcerated populations. Changing the thinking about substance abuse treatment for incarcerated populations has been challenging, 
especially since there has not yet been a treatment that has been proven successful for long term outcome (Grietens \& Hellinckx, 2003).

Only approximately $40 \%$ of juvenile facilities across the United States offer treatment for drug offenders (Thornberry, Tolnay, Flannigan, \& Glynn, 1991). Most of these treatments are modeled after those conducted with non-adjudicated adolescents, or incarcerated adults (Webb, et al, 2002). Many of the treatments provided to incarcerated, substance-abusing adolescents have different focuses and modalities, and lack specific drug abuse elements. Some of the more common substance abuse treatments for incarcerated juveniles include Residential Treatment, Therapeutic Communities, Boot Camp programs, Milieu Therapy, Relapse Prevention, and self-help programs (SAMSHA, 1995). Each of these treatments will be briefly discussed.

Residential Treatment (RT) designed for offenders incorporates several different models and philosophies with variable lengths of stay. RT incorporates individual and group components with differing intensities. The RT programs designed for offenders often use a group treatment approach to create an environment that duplicates certain aspects of functional family relationships. Creating this environment for the residents is meant to foster collaboration and communication among the group. Parts of most residential treatment programs incorporate a segment on substances of abuse, and can be tailored to the audience being treated (Epstein, 2004; Grietens \& Hellinckx, 2003; Jainchill, Hawke, \& Messina, 2005; Orlando, Chan, \& Morral, 2003; Rosenheck \& Seibyl, 1998; SAMSHA, 1995).

Therapeutic Communities (TC) are a type of residential program meant to help individuals phase into independent living. The intention of TC is to promote global 
changes in life-style, attitudes, and values. The treatment is highly structured and incorporates a number of life services in a single setting. Services include education, medical, family, legal, and social services as well as counseling, individual therapy, and group therapy (California Dept. of Corrections, 1999; Jainchill, Hawke, \& Messina, 2005; Lipton,1996; SAMSHA, 1995). Therapeutic communities are one of the more common therapies used in juvenile correctional settings for substance abuse treatment (SAMSHA, 1995).

Boot Camp Programs (BCP) were created as a response to mandatory drug sentencing. Currently 27 states have $\mathrm{BCP}$ camps with 47 camps total. The $\mathrm{BCP}$ is highly regimented, military-styled discipline, combined with confrontation, and behavior modification (Pearson \& Lipton, 1999; SAMSHA, 1995).

Milieu Therapy (MT) is similar to but less intensive than therapeutic communities. MT is generally carried out in an isolated, drug-free living area within the prison. It incorporates group and individual counseling, and often uses confrontational group sessions and peer interaction (LeCuyer, 1992; SAMSHA, 1995; Weid \& Lutova, 2002).

Relapse Prevention (RP) and Self Help (SH) are generally given in conjunction with another form of treatment, for example TC. The focus of RP is behavior modification. RP teaches individuals to recognize their triggers for substance use, and provides participants with situation-specific tools to avoid using. SH groups are commonly referred to as 12 step programs (i.e., AA, NA). These forms of treatment bring the individual through a series of 12 steps to change their behavior emphasizing 
the importance of seeking guidance from religion and/or a higher power (Parks \& Marlatt, 1995; SAMSHA, 1995).

Researchers have shown that effective programs share elements that include targeting the offender's cognition, self-evaluation and expectations, and focus on changing the participant's view of the world and societal values (Izzo \& Ross, 1990). Overwhelmingly what has emerged from this research is that a program's effectiveness depends not only on the elements of the program, but also on the experience / training of the treatment providers, how the program is targeted, the treatment setting, by whom it is administered (i.e. treatment providers within the residential setting vs. an outside vendor; Izzo \& Ross, 1990; Parks \& Marlatt, 1995; Pearson \& Lipton, 1999). More often than not, treatment in prison facilities is often dictated not by clinical research recommendations, but by funding agencies. This leaves large gaps in the organization and management of critical elements of the treatment program with respect to fidelity or implementation, quality of treatment being offered, and understanding of the clinical phenomena of interest (Lipton, 1999). Programs cannot be duplicated and retested for long-term usefulness without placing more emphasis on experimental research to evaluate the effectiveness of the program controlling for the specifics of the treatment models, the training and credentials of staff members, treatment delivery, and supervising procedures. Juvenile detention facilities may provide a useful venue for doing just that, and more specifically, for furthering extant knowledge of adolescent marijuana use. This could lead to more insight into the reasons for initiation and continued use, and would monitor the adherence to treatment programs for a more indepth understanding of the components that contribute to long-term change. The 
expectation is that this research will guide understanding of the factors that influence marijuana abuse among incarcerated adolescents and subsequently pave the way for more tailored treatments. This is important particularly given the high rates of marijuana use and misuse among incarcerated adolescents.

The larger clinical trial from which these data are taken utilized randomized treatment assignment to investigate the effects of Motivational Intervention (MI) and Relaxation Therapy (RT) on group participation rates within the training facility, described elsewhere (Stein, Colby, Barnett, Monti, Golembeski, Lebeau-Craven, \& Miranda, 2006). The larger study investigates which treatment option (MI vs. RT) is more effective at reducing marijuana use among juveniles three months after release from incarceration. Further, secondary analysis of this data will be explored to determine which treatment (MI vs. RT) is more useful for adolescents who use marijuana to regulate their emotions (i.e., to reduce tension). The proposed study will inform the results of the main analyses of the larger clinical trials.

The proposed study will also examine several of these background variables (family and peer history of use, age of onset, and sexual victimization) as predictors of more serious marijuana use (defined as abuse by the SCID) among a group of incarcerated adolescents. Additionally, reasons for marijuana use, marijuana expectancies and use of marijuana for emotional regulation will be examined, utilizing the Marijuana Effects Expectancy Questionnaire and the Brief Situational Confidence Scale. Using marijuana to regulate negative affect, defined as having high expectancies for the effects of marijuana to help one relax and reduce tension, and a low confidence score for not smoking in situations where negative feelings will be alleviated will form 
a negative affect factor. A distinct factor should emerge identifying those who use marijuana for positive affect, defined as having: a high expectancy for marijuana to make parties with friends more fun and make one more social, and a low confidence for not smoking in situations that involve celebrating with friends and enjoying oneself at a party.

\section{Rationale for Current Study and Significance}

The proposed research project has a number of important potential implications for furthering basic knowledge and assisting in the implementation and development of future marijuana treatment efforts with incarcerated adolescents. Moreover, intervening with incarcerated adolescents who use marijuana could help to reduce recidivism and improve the overall health of this underserved population.

\section{Potential Implications of this Research}

Preliminary pilot work in detention indicates that a substantial number $(83 \%)$ of adolescents are reporting daily marijuana use (Stein et al., 2006). This illustrates a need for more specialized treatment and appropriately trained intervention specialists to provide substance use treatment to these teens. The proposed research study may help to identify factors that make teens more likely to be marijuana users and the type of treatment that is more effective for their individual needs. This could potentially decrease the amount resources needed to treat incarcerated adolescents by providing a more efficient and cost effective way to reduce marijuana use among this population.

A great deal of research is needed to better understand marijuana use and effective treatment among the incarcerated adolescent population. This research will 
improve the efficacy of treatment for both male and female adjudicated adolescent populations by gaining a better understanding of the reasons for marijuana use, and subsequently adding to the knowledge base of marijuana treatment for these adolescents.

\section{The Current Study}

The current study was designed to extend basic knowledge of the reasons for marijuana use, establish factors related to marijuana use, and examine if relaxation therapy reduces marijuana use in those who use marijuana as a way to regulate emotions.

\section{Hypotheses}

1. It is hypothesized that, upon entrance to a juvenile training facility, youth who abuse marijuana will report a related set of background variables (e.g., family history of substance use, peer history of substance use, and personal use for emotional regulation) that differs from youth who do not have a marijuana abuse diagnosis.

a. It is hypothesized that for teens who present with negative affectivity, relaxation therapy will be more effective than motivation intervention for reducing marijuana use 3 months after release.

2. Based on previous research (Stephens, Wertz, \& Roffman, 2004), it is hypothesized that upon entrance to a juvenile training facility, youth with negative affect (defined as having high expectancies for the effects of marijuana to help one relax and reduce tension, and a low confidence score for not smoking in situations where negative feelings will be alleviated) will 
have elevated marijuana use compared to those with positive affect (high expectancy for marijuana to make parties with friends more fun and make one more social, and a low confidence for not smoking in situations that involve celebrating with friends and enjoying oneself at a party).

3. It is hypothesized that adolescents with a record of childhood sexual abuse will report more marijuana use upon entrance to the training facility.

4. It is hypothesized that adolescents with a record of childhood sexual abuse will be more likely to use marijuana for negative affectivity than for positive affectivity.

Method

\section{Participants}

One hundred and ninety-one incarcerated adolescents aged 14-19 $(\underline{M}=17)$ were recruited for a larger treatment study described elsewhere (Stein, et al., 2006), in which participants and their guardians consented to participate. Potential participants adjudicated between January 2001 and September 2005 were included in the larger study if they met any of the following criteria: a) in the year prior to incarceration they used marijuana or alcohol at least monthly; b) they used marijuana or drank in the month preceding the offense for which they were committed; or c) they used marijuana or drank in the month preceding commitment. A total of 417 potentially eligible adolescents were identified. For 170 youth, parents/guardians could not be reached for consent, 45 could not be recruited due to project staff not having enough time to complete the assessment and treatment at baseline, and 7 were not interested in participating. Of the 195 who consented and participated in the study, 6 dropped out 
prior to completion of baseline assessment due to early release or loss of interest in participating.

The population at the training school is diverse. The demographics of the project sample are comparable to the population of the facility. Of the 189 participants, $86 \%$ were boys, $32.8 \%$ White, $29.1 \%$ Hispanic/Latino, $28 \%$ African American, and $10.1 \%$ other. The age breakdown was as follows: $6.3 \% 14$ year olds, $7.2 \%$ age 15 , $27.2 \%$ age $16,35 \%$ age $17,22.2 \%$ age 18 , and $2.1 \% 19$ year olds. Reasons for incarceration range from simple truancy to possession with intent to sell. The average length of time incarcerated was between 4 and 12 months (inclusive).

Procedures

All procedures were approved by the Brown University, The University of Rhode Island Institutional Review Boards, and by the Rhode Island Training School (RITS) research review committee (See Appendix A). Participants were identified through daily contacts with each of the seven units that house adjudicated adolescents. Consent for adolescents to participate was obtained from guardians and an assent was signed by the adolescents themselves. Guardians and teens were presented with a description of the study including procedures, potential risks and benefits, and confidentiality, and asked to sign a consent form. Assessments were conducted in private rooms with Bachelor's- or Master's-level research interviewers. Condition assignment was revealed at the end of the assessment and a time to complete the baseline treatment was selected. The treatment was completed within one week of completing the baseline assessment by the same researcher that completed the 
assessment. Each of the research interviewers were extensively trained over a threemonth period in the methods of treatment used and the project protocol.

\section{Treatment conditions.}

Following assessment, participants were randomly assigned to one of two treatment conditions, Relaxation Therapy (RT; 48\%) or Motivational Intervention (MI; $52 \%$ ), both designed to help prepare them for the facility's standard care treatment. This standard care treatment included (list generally what happens to kids while there)

The two treatment conditions (MI and RT) each took approximately 90 minutes during one session at baseline and 60 minutes during a second, booster session. Interventions were conducted by a trained Bachelor's- or Master's-level staff following a manualized treatment protocol. Interviewers go through three months of training on the interventions and the protocol. Additionally, the interviewers received one hour of individual and one hour of group supervision per week with a Ph.D.-level project member.

Motivational Intervention. In MI the intervention is modified for each participant based on the answers given during the baseline assessment and his or her interest in changing. The intervention consisted of four components: establishing rapport, assessing motivation for change, enhancing motivation, and establishing goals to aid in making changes. Establishing rapport aims to present the counselor as empathic, concerned, non-authoritarian, and non-judgmental, elements presented by Miller (1995) as essential to MI. In order to assess a participant's motivation to change, a number of questions about the participant's likes and dislikes about using marijuana were asked. These were then used by the counselor to personalize the pros and cons of 
use while understanding the participant's readiness level toward making a change. In order to enhance motivation the counselor presents and discusses individualized feedback based on participant's answers. The feedback consists of four kinds of information: (a) the participant's marijuana use; (b) the characteristics of dependence on marijuana; (c) marijuana-related consequences; and; (d) the participant's prominent marijuana-related outcome expectancies along with information to counter their authenticity.

The next stage of the intervention involved examining the participant's sense of discrepancy between his/her current behavior and future goals while serving to increase his/her ambivalence about his/her current behavior. Portions of the MI are also devoted to instilling a sense of self-efficacy to guide participants toward wanted behavior change and a discussion regarding what they want to do differently in terms of their marijuana use.

Relaxation Therapy. In RT participants were instructed in using muscle relaxation and meditation as a behavior management tool. Participants received feedback on their use of the techniques as well as handouts on relaxation methods. The treatment providers maintained rapport and provided generalized advice to stop use of marijuana, criminal behavior, and risky activities.

Follow-up.

Two follow-ups were completed. An in-facility follow-up was conducted two months after the initial interview. This follow-up consisted of assessments and a treatment booster. The treatment booster was given to participants in both treatment groups and essentially repeated the original discussion with the adolescent. Upon 
completion of the in-facility follow-up, research staff obtained extensive contact information to complete the second follow-up which occurred at 3-months post-release. The 3-months post-release follow-up was completed on average 61 days from the baseline assessment. Assessments were conducted by a trained research assistant who was blind to treatment condition. Participants were compensated for their time in the study by receiving a meal for participation while still in facility and $\$ 50-\$ 60$ in gift cards to the local mall for the 3 month post-release participation (see Table 1).

\section{Measures}

A copy of all of the questionnaires is found in Appendix B.

Background Questionnaire. Sociodemographic information was recorded at baseline, including: parent alcohol/drug history; peer alcohol/drug involvement; age of onset of alcohol/drug use; and age youth began to use regularly. This questionnaire was developed by Stein and colleagues for the original study based on their work in juvenile and adult correctional facilities. Additionally, sexual abuse is recorded via review of background files kept at the facility on each teen. Any history of abuse is recorded and kept in individual teen records.

BSCQ-M. The Brief Situational Confidence Questionnaire (Breslin, Sobell, Sobell, \& Agrawal, 2000) is a state-dependent measure that assesses self-confidence to resist the urge to use marijuana in a variety of situations. The Brief version consists of 8-items derived from the original 100-item questionnaire. Based on Marlatt and Gordon's (1980) content analysis of clients' descriptions of relapse determinants, the BSCQ includes eight situations: 1) negative emotional states; 2) negative physical 
states; 3) positive emotional states; 4) testing personal control; 5) urges and temptations; 6) interpersonal conflict; 7) social pressure; and 8) positive emotional states.

The BSCQ first asks people to imagine themselves as they are "right now" in each of the eight situations noted above. They are then asked to indicate on a scale from $0 \%$ ("not at all confident") to $100 \%$ ("totally confident") how confident they are to resist using marijuana in each of the eight situations. The BSCQ has been tested with high-risk drinkers and has shown to correlate well with the subscales from the original 100 item version it has also shown to have a high level of internal consistency (alpha $=.85$ ). Psychometric validation has not been completed on the marijuana version of the assessment.

CES-D. The Center for Epidemiological Studies Depression Scale is a 20 -item self report scale designed by Radloff (1977) to measure depressive symptoms in the general population (Barlow, 1998). The Center for Epidemiologic Studies Depression Scale (CES-D) assesses the presence and severity of depressive symptoms occurring over the past week (Carpenter, Andryowski, Wilson, Hall, Rayens, Sachs, \& Cunnigham, 1998) on a scale ranging from $0-3$ with: $0=$ rarely or none of the time $(0$ days); $1=$ some or little of the time ( $1-2$ days); $2=$ occasionally or a moderate amount of time ( $3-4$ days); and $3=$ most or all of the time $(5-7$ days). A total depressive symptom score is calculated. It has been shown to detect adult patients with depressive symptoms fairly accurately in primary care settings, with sensitivities and specificities that vary depending on the cutoff score selected. For example, the CES-D has been shown to have a sensitivity of $89 \%$ and a specificity of $70 \%$ at a cutoff score of 27 (Mulrow, 1995). In addition, the adult CES- D has been tested on adolescents with a 
sensitivity of $84 \%$ and a specificity of $75 \%$ at a cutoff score of 24 (Schulberg, McClelland, Gangul, Christy, \& Frank, 1985).

$M E E Q-B$. The Marijuana Effects Expectancy Questionnaire (MEEQ) was developed by Shafer and Brown (1991) to examine the effects attributed to marijuana that the individual anticipates experiencing when using marijuana and as a means of identifying a respondent's perceptions or expectations of marijuana. Content and factor analyses were conducted by the authors to define the domain of adolescent marijuana expectancies, revealing six factors: cognitive and behavioral impairment, relaxation and tension reduction, social and sexual facilitation, perceptual and cognitive enhancement, global negative effects, and craving.

A brief version was developed (MEEQ-B; Torrealday, Stein, Colby, Barnett, Monti, Golembeski, \& Lebeau-Craven, 2005) consisting of 6 items. Adolescents are asked to rate each of the 6 items on a scale from 1 (disagree strongly) to 5 (agree strongly). A principal components analysis was run on the briefer 6-item version and two factors emerged. One factor consists of general negative effects ("Marijuana makes it hard to think and do things"; "Marijuana generally has bad effects on a person"; and "Marijuana has effects on a person's body and gives a person cravings"). The general positive effects factor consists of the following "Marijuana helps a person relax and feel less stress", "Marijuana helps people get along better with others and can help you feel more sexual", and "Marijuana makes a person feel more creative and perceive things differently". These two factors accounted for $52 \%$ of the variance and internal consistencies were comparable to the original assessment (.51; Torrealday, et al, 2005). 
SCID-I, Substance Use Diagnosis for Marijuana. The Structured Clinical Interview for DSM III-R (Spitzer, Williams, Gibbon, \& First, 1990) is a semi-structured interview used for formulating a major Axis I DSM diagnosis. There are nine modules that can be adapted for use separately depending on research interest. The instrument uses a decision tree to guide the SCID administrator as the interview is conducted. Current as well as lifetime occurrence is recorded. Reliabilities for the substance use module are adequate to good with Kappas ranging from .84-.95 (Skyre, Onstad, Torgersen, \& Kringlen 1991; Williams, Gibbon, First, Spitzer, Davis, Borus, et al., 1992; Zanarini \& Frankenburg, 2001). Although research has been variable in terms of validity for the substance abuse module, other research suggests good predictive validity for marijuana (Kranzler, Kadden, Babor, et al., 1996).

TLFB-Marijuana. Time-Line Followback (Sobell, Maisto, Sobell, \& Cooper, 1979) is a calendar-assisted measure based on a subject's retrospective account of his/her drinking and drug use behavior over a specified time period. TLFB has been shown to have excellent reliability (.79-.98; Sobell et al., 1979; Sobell, Sobell, Leo, \& Cancilla, 1988) and high content, criterion, and construct validity in clinical and non clinical populations (Connors, Watson, \& Maisto, 1985; Sobell, Sobell, Klajner, \& Pavan, 1986). The TLFB was adapted for marijuana use for this study and asks adolescents to recall their marijuana use based on amount of marijuana used and how often they use each day for a 90 -day period. These data were collected for the 90 days prior to sentencing and for the 90 -days after release. Teens were assessed within one month of sentencing. 


\section{Data Analyses}

The data are stored off training school grounds at the University of Rhode Island. The software system used to analyze the data was SPSS (Statistical Package for the Social Sciences, version 11.0 SPSS, Inc., Chicago, IL). The present study utilized this archival data to conduct data analysis in two phases. Phase 1 addresses data cleaning including the handling of missing data. Phase 2 directly tests the aforementioned hypotheses.

\section{Phase 1: Preliminary Data Analyses}

Data cleaning and handling missing data was based on the recommendations of Tabachnick and Fidel (2001). Descriptive analyses were conducted to be sure that all of the assumptions of normality and linearity were met and missing data were handled using the Expectation Maximization (EM) procedure. However, there were not large amounts of missing data due to the placement of the participants (i.e., teens are incarcerated and easily accessible) and the way data were collected via an interviewer.

\section{Phase 2: Data Analyses Addressing Dissertation Hypotheses}

Prior to investigating the hypotheses, descriptive statistics were computed on all variables to be examined in the subsequent analyses. The demographic characteristics of the sample are reported. The means and standard deviations were examined for the items comprising predictor variables (parent and peer substance use history, age of first marijuana use, sexual abuse history, depression, expectancy scores, confidence scores (see attached measures), marijuana diagnosis and treatment condition. Finally, Pearson product-moment correlations were computed among predictor and dependent variables. 
It is hypothesized that, upon entrance to a juvenile training facility, youth who abuse marijuana will report a related set of background variables (e.g., family history of substance use, peer history of substance use, and personal use for emotional regulation) that differs from youth who do not have a marijuana abuse diagnosis. Hypothesis 1 was explored using factor analysis on items representing the circumstances of marijuana use among the population of adolescents. The items were grouped a priori according to the theoretical concepts they were originally created to represent. Here we were interested in examining the items that are conceptually similar to determine if they are also statistically similar. Also, these analyses were used to determine more specifically what the underlying factors are, if any, within each item grouping. This technique was proposed and discussed by Tabachnick and Fidell (2001).

Hypothesis 2 states that: upon entrance to a juvenile training facility, youth with negative affect will have elevated marijuana use (defined as abuse on the SCID) compared to those who do not have negative affect. A negative affect variable was created using three items from the BSCQ to test this hypothesis. A Multivariate Analysis of Variance (MANOVA) will be used to examine the difference between those with negative affect and those with positive affect as the independent variables (IV's) and level of marijuana use at baseline (number of joints smoked per day and average number of joints smoked per week) as the dependent variables (DVs).

Hypotheses 3 and 4 state that: adolescents with a record of childhood sexual abuse will report more marijuana use upon entrance to the training facility and will be more likely to use marijuana as a method of emotional regulation. These analyses, 
examining the effect of childhood sexual abuse on the relationship between reason for use (negative vs. positive affectivity) and intensity of use, were compared by an additional MANOVA with history of sexual abuse as the IV and baseline levels of marijuana use (number of joints smoked per day and average number of joints smoked per week) as DVs.

Exploratory analyses will also be conducted to gain needed information on differences between male and female juvenile detainees in terms of reasons for use, relevant background variables (e.g., family history, peer use history), and treatment effects. These analyses are meant to be exploratory with the expectation of promoting further research in this area, adding to the knowledge base, and ultimately expanding the literature in this area.

Results

Before examining the hypotheses, distributions of all variables used in this study were checked. There were two Timeline follow-back variables (average number of joints smoked per week in the past three months and frequency of marijuana use in the past three months) that did not have normal distributions. As a result, outliers were coded as one unit higher than the highest non-outlier data point. This transformation brought skewness and kurtosis of these variables within the normal range.

The test of the first hypothesis was conducted using principal components analysis (PCA) with varimax rotation on the item intercorrelation matrices. The number of components to retain was determined using the minimum average partial procedure (MAP; Velicer, 1976) and parallel analysis (Horn, 1965). These two methods have 
been found to be accurate for determining the number of components to retain (Zwick \& Velicer, 1986).

Fifteen items were included in the exploratory factor analysis (6 MEEQ items \& 9 BSCQ items; see Table 2). PCA with varimax rotation on the 15 X 15 matrix of item intercorrelations was conducted to determine the factor structure of the scale. MAP suggested 1 factor and parallel analysis suggested 2 factors. The hypothesis was that the MEEQ \& BSCQ items would load together and two resulting factors would emerge (negative affect and positive affect). After examining both solutions, it was apparent that these two scales were not melding together in any way. The single factor solution suggested by the MAP criterion demonstrated that only the BSCQ items were loading on the scale and the MEEQ items had very poor loadings on this single factor.

The 2-factor solution suggested by the parallel analysis criterion separated the BSCQ items from the MEEQ items. Two of the MEEQ items "loaded" on the BSCQ factor. Actually, loadings less than .40 are not considered strong enough loadings to be considered on that factor (see Table 3).

Since the exploratory factor analyses did not reveal a negative affect/positive affect factor structure, negative affect was derived from three items on the BSCQ scale. These items include: negative emotional states (Item 1); negative physical states (Item 2); and interpersonal conflict (Item 6). If a participant endorsed having little to no confidence $(\leq 25 \%)$ on any two of these three items then they would score positive for negative affect.

Next, a one-way Analysis of Variance (ANOVA) was run to examine differences in depression as measured by the CES-D scale among those with greater 
negative affect $(M=21.35)$ versus those with less negative affect $(M=20.6)$. There were no significant differences on the CES-D scale between the groups with differing levels of the negative affect variable, $F(1,187)=.208, p>.05$, eta-squared $=.001$ (see Figure 1 ).

Hypothesis la was first analyzed using analysis of covariance (ANCOVA). ANCOVA was chosen in order to include baseline levels of marijuana use as a covariate. Only those who had been classified as having negative affect on the calculated variable were included in these analyses. Two separate ANCOVAs were run. The first assessed average number of joints per week at 3 month follow-up as the DV with treatment condition (MI vs. RT) as the IV. The second used the number of days smoked at 3 month follow-up as the DV and treatment group as the IV. There were no significant differences in either ANCOVA, $p>05$.

Since no significant differences were found in the previous analyses, two additional $2 \times 2$ ANCOVAs were run, for treatment group (MI vs. RT) X affect level. Number of joints per week at three month follow-up was the DV for the first analysis; number of days smoked for the second, and the corresponding baseline level (i.e., number of joints per week and number of days smoked at baseline assessment) were the covariates. There were no significant differences found in these new analyses. However, the covariate in these analyses was significant, showing the importance of using the baseline variable of marijuana use as a covariate, as it was significantly related to marijuana use at the follow up.

Hypothesis 2 was examined utilizing two 2 x 2 MANOVAs with negative affect (yes/no) and positive affect (yes/no) surrounding marijuana use as the IVs, and baseline levels of average marijuana use per week and number of days smoked marijuana as the 
DVs. The results are as follows: the multivariate tests for negative affect $(F(1$, $176)=8.18, p<.001$, eta-squared $=.085)$ and positive affect $(F(1,176)=4.00, p<.05$, etasquared=.043) were significant; but the interaction of negative and positive affect was not significant $(F(1,176)=.440, p>.05$, eta-squared $=.005)$.

The between-subjects tests that follow the MANOVA reveal significant differences for negative affect on both average number of joints per week $(F(1,177)=9.44, p<.01$, eta-squared $=.05 ; M=49.6$ for negative affect group and $M=26.2$ for non; see Figure 2) and number of days marijuana was smoked $(F(1,177)=15.24$, $\mathrm{p}<.001$, eta-squared=.08; $M=69.2$ for negative affect group and $M=46.4$ for non; see Figure 3).

While the Positive Affect was significant for number of days smoked in past 3 months $(F(1,177)=5.31, p<.05$, eta-squared $=.029 ; M=64.9$ for positive affect group and $M=53.4$ for non; see Figure 4), it was not significant for the average number of joints per week $(F(1,177)=.012, p>.05$, eta-squared=.00; $M=37.9$ for positive affect group and $M=37.9$ for non; see figure 5).

Hypothesis 3 was examined using 2 (abuse) $\times 2$ (positive/negative affect) MANOVAs with the effect of childhood sexual abuse on the relationship between reason for use (e.g., negative affect versus no negative affect and positive affect versus no positive affect) and intensity of use. Sexual abuse was the IV with average number of joints per week as the DV for the first MANOVA. The second was sexual abuse as the IV with number of days smoked as the DV. There were no significant differences in terms of sexual abuse history for either DV: those with sexual abuse histories smoked 
$M=40.7$ joints per week on $M=55.6$ days; those without smoked $M=41.4$ joints per week on $M=60.9$ days.

Finally, exploratory analyses were conducted to determine if there were gender differences in terms of reasons for marijuana use, relevant background variables (e.g., family history, peer use history), or treatment effects using ANOVA and Chi-Square statistics. The significant findings were as follows: females had a higher rate of family history of substance abuse than did males $(F(1,187)=7.02, p<.01 ; M=5.93$ females and $M=4.46$ for males); and significantly more females reported that marijuana generally has bad effects on a person causing anger and carelessness than did males $(F(1,187)=5.22, p<.05 ; M=4.78$ females and $M=4.70$ for males $)$. There were no further significant gender differences revealed in this data set.

\section{Discussion}

With juvenile drug testing as a priority in American correctional facilities, resulting in a doubling of the rate of drug tests among this population (Bureau of Justice Statistics, 1999), more juvenile detainees are testing positive for marijuana use. This, in turn, increases drug enforcement among this population, as well as the demand for treatment (SAMSHA, 2001; Webb, et al., 2002). Increasingly, adolescents are courtordered to substance abuse treatment while incarcerated, or are court-ordered to inpatient treatment in lieu of incarceration (Webb, et al., 2002).

The purpose of this project was to identify reasons for marijuana use among incarcerated adolescents. It was hypothesized that reasons for use would be separated into two groups, those who use marijuana for reducing personal issues (negative affect) and those who use marijuana to celebrate and have more fun with their friends. These 
groups, separated by the reasons that one uses marijuana, would then result in differences in quantity and frequency of use. An attempt was made to show that adolescents giving different reasons for use (positive versus negative affect) would differ significantly on marijuana use variables at baseline, and that the two groups of adolescents would show further differences in response to the two different treatments (MI versus RT) at the 3-month follow-up. Additionally, sexual abuse history was investigated as a predictor of marijuana use. Finally, gender differences among this population to examine variation in marijuana use, expectancies and confidences, as well as family history and peer substance use between incarcerated male and female adolescents were explored.

A principal components analysis on the Brief Situation Confidence Questionnaire (BSCQ) and the Marijuana Effects Expectancies Questionnaire (MEEQ) did not reveal separate factors that represent reasons for marijuana use. In fact, the scales remained almost completely intact. In order to test the hypotheses of this study, items from the BSCQ that corresponded with low confidence to avoid marijuana use in situations were included in a negative (either mentally or physically) affect variable. A positive affect variable was also calculated, using the items from the same scale that corresponded with low confidence to avoid marijuana in situations that relate to using marijuana for enjoyment or celebrating (i.e., recreational use).

Most of the analyses did not reveal significant differences between marijuana users with negative affect and those users with positive affect, with respect to reasons for marijuana use, family history, depression, peer history, or quantity of marijuana use at 3 month follow-up. 
However, there were significant findings that support the thinking behind the original hypotheses. While incarcerated adolescents who were in the negative affect group (negative affect yes) and the positive affect groups (positive affect yes) had higher averages of weekly marijuana use. Only those in the negative affect group (negative affect yes) had a higher number of days using marijuana at 3-month follow-up than did those who were not in the negative affect group (negative affect no). This was true regardless of treatment group, and when baseline levels of use were covaried out. Those in the positive affect group reported no difference in the average number of "joints" smoked per week in the past 3 months. This may support the hypothesis that those with negative affect will use marijuana more frequently than those using for recreation. As mentioned, other researchers have examined and advocated for the hypothesis that teens use substances for the purpose of self-medication (Aharonvich, et al., 2001; Green, et al., 2004; Khantzian; 1997, Loeber et al., 1999; Mueser, et al., 1998). In fact, there is some evidence that affective states (i.e., negative emotions) may have a general, yet important, role in substance use in general (Chassin, et al., 1993). Past research also indicates that low self-esteem, sadness and depression, as well as low self-efficacy, were associated with adolescent marijuana use (Babor, 2002; Stephens, et al., 2004). Further, research indicates that boys aged 7-18 who reported mood disregulation (e.g., depressive mood and anxiety) were more likely to use marijuana as a form of self-medication (Loeber, et al., 1999).

In addition significant gender differences were found, with females reporting a more considerable family history of drug use and reporting that they perceive that marijuana has bad effects on a person, compared to males. One explanation for these 
findings may be that males and females react differently, with males tending to exhibit externalizing behaviors and females tending to exhibit internalizing behaviors (Rhodes \& Fischer, 1993; Storvoll, Wichstrom, \& Pape, 2003; Webster-Stratton, 1996). Reasons for referral to a detention facility, for example, differed between males and females, with males more likely to be referred for violations of the law, including selling drugs, while females were more likely to be referred for status offenses such as running away from home (Rhodes, et al., 1993). Specifically of interest, researchers also found a correlation between what they termed predictor variables (self-reported drug use and delinquency) and later arrest. For females, physical abuse in the home was associated with status offenses, while this was not the case for males (Dembo, et al., 1995). The finding that females report more history of drug use in the home may suggest an alternate hypothesis: the experience of living with such abuse may lead to an aversion to use and may also lead to viewing drug use as more detrimental to a person, more so than for males. Relating this back to the previous rationale, females may be more likely to see the negative side of marijuana use than males, as indicated by the higher rate of family history reported.

Marijuana use is extremely common among incarcerated adolescents (LebeauCraven, et al., 2003). Gaining knowledge about the reasons for marijuana use, and about effectiveness of treatment approaches for incarcerated youth, could potentially have a powerful impact on marijuana users post-incarceration.

Several of the hypotheses did not have significant results. There are various limitations that may have contributed to these findings. This was an exploratory study based on archival data that were self-reported and therefore could be inaccurate. It is 
possible that some adolescents under-reported their use of marijuana as well as their confidence for being in situations where they would not use marijuana. Others may have exaggerated their use and confidence levels. The sample was predominantly male (approximately $86 \%$ of the sample) as well, making the findings more difficult to interpret or generalize for incarcerated adolescent females. Further, this study involves a relatively small sample of incarcerated adolescents. Including additional participants at multiple sites would not only increase the statistical power, but would also increase generalizability among incarcerated adolescents. Finally, the small sample size, combined with the fact that most adolescents who are incarcerated use marijuana, come from similar backgrounds (including socio-economic status), and have significant traumas in their lives (when compared to general population estimates; Bloom, Owen, Deschenes, \& Rosenbaum, 2002; Dembo, Schmeidler, Chin Sue, Borden, \& Manning, 1995, Wood, Foy, Layne, Pynoos, \& James, 2002) may make the examination for specific distinctions in reasons for marijuana use among this population all the more difficult.

As a result, further research is needed to examine the hypothesis that incarcerated adolescents who begin using marijuana as a way to neutralize emotions can be distinguished from those who use marijuana for recreation or social experience. More research on this issue will allow for a better understanding of how to shape treatment efforts in this population. It is important to understand the perceived benefits of using marijuana among incarcerated adolescents, and how those perceptions may mediate continued use. This could inform not only methods to encourage cessation but could potential inform prevention efforts as well. In terms of the experimental 
treatments tested in this protocol, self-medication may be best treated by utilizing techniques which do not involve drugs to facilitate new ways of dealing with difficult situations.

This population is also ethnically diverse. In addition, females are often not included as part of the sample when researching incarcerated adolescents due to the significantly smaller number of incarcerated adolescent females. As a result, both ethnicity and gender should be included in further investigations into the motivations for marijuana use, quantity and frequency of use, as well as treatment implications.

There is an increased need for assessing marijuana use among this population because the reasons for initiating and continuing use are still unclear. Future research will need to explore factors (e.g., family history, peer history, reason for use) that relate to marijuana use among incarcerated adolescents in terms of using marijuana as a way to regulate emotions versus using marijuana as a recreational tool. This will help to better inform treatment efforts in training facilities and among the incarcerated adolescent population. Further, previous research does promote the value of future studies that focus on reasons for marijuana use and treatment in this population. 
Table 1

Project flow chart:

Baseline Assessment and Treatment
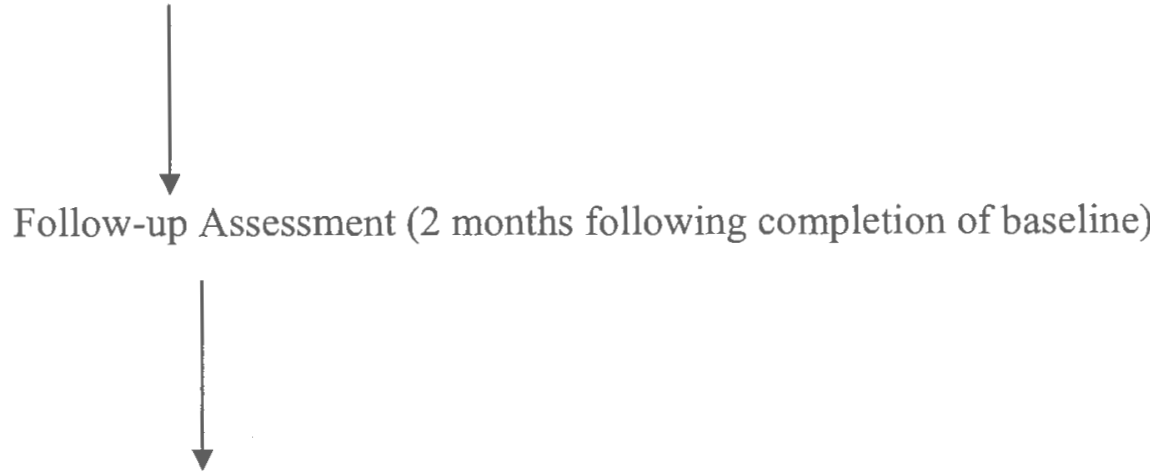

Booster Treatment and Assessment ( 2 weeks prior to release date)

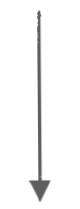

Follow-up Assessment ( 3 months post release) 


\begin{tabular}{|l|l|l|}
\hline \multicolumn{1}{|c|}{ Table 2: } & \multicolumn{1}{|c|}{ PCA - 1 Factor Solution } & Factor Loading \\
\hline PRBSQM5r & urges \& temptations - mj & -.848 \\
\hline PRBSQM1r & unpleasant emotions - mj & -.847 \\
\hline PRBSQM8r & pleasant times w/other - mj & -.841 \\
\hline PRBSQM6r & conflict w/others - mj & -.821 \\
\hline PRBSQM3r & pleasant emotions - mj & -.815 \\
\hline PRBSQM2r & phsyical discomfort - mj & -.798 \\
\hline PRBSQM9r & school/work problems - mj & -.767 \\
\hline PRBSQM7r & pressure to use - mj & -.766 \\
\hline PRBSQM4r & testing control over mj & -.704 \\
\hline PRMEEQB1 & makes it harder to think & -.329 \\
\hline PRMEEQB3 & MJ helps people get along better & .327 \\
\hline PRMEEQB4 & MJ makes person more creative & .313 \\
\hline PRMEEQB5 & MJ has bad effects on person & -.265 \\
\hline PRMEEQB2 & MJ helps a person relax & .223 \\
\hline PRMEEQB6 & MJ has effects on persons body & -.021 \\
\hline
\end{tabular}




\begin{tabular}{|c|c|c|}
\hline \multicolumn{3}{|c|}{ PCA - 2 Factor Solution } \\
\hline \multicolumn{3}{|c|}{ Factor 1} \\
\hline Item & Question & $\begin{array}{l}\text { Factor } \\
\text { Loading }\end{array}$ \\
\hline PRBSQM1r & unpleasant emotions $-\mathrm{mj}$ & .826 \\
\hline PRBSQM2r & physical discomfort $-\mathrm{mj}$ & .777 \\
\hline PRBSQM3r & pleasant emotions $-\mathrm{mj}$ & .826 \\
\hline PRBSQM4r & testing control over mj & .723 \\
\hline PRBSQM5r & urges \& temptations - mj & .848 \\
\hline PRBSQM6r & conflict w/others - mj & .800 \\
\hline PRBSQM7r & pressure to use $-\mathrm{mj}$ & .778 \\
\hline PRBSQM8r & pleasant times w/other $-\mathrm{mj}$ & .841 \\
\hline PRBSQM9r & school/work problems - mj & .769 \\
\hline PRMEEQB1 & MJ makes it harder to think and do things. & .338 \\
\hline PRMEEQB5 & $\begin{array}{l}\text { MJ generally has bad effects on a person (you become } \\
\text { angry and careless; after feeling high you feel down) }\end{array}$ & .312 \\
\hline \multicolumn{3}{|c|}{ Factor 2} \\
\hline Item & Question & $\begin{array}{l}\text { Factor } \\
\text { Loading }\end{array}$ \\
\hline PRMEEQB3 & $\begin{array}{l}\text { MJ helps people get along better with other and it can } \\
\text { help you feel more sexual. }\end{array}$ & .726 \\
\hline PRMEEQB4 & $\begin{array}{l}\text { MJ makes a person feel more creative and perceive } \\
\text { things differently. }\end{array}$ & .716 \\
\hline PRMEEQB2 & MJ helps a person relax and feel less tense. & .701 \\
\hline PRMEEQB6 & $\begin{array}{l}\text { MJ has effects on a person's body and gives a person } \\
\text { cravings. }\end{array}$ & .329 \\
\hline
\end{tabular}

\begin{tabular}{|l|r|r|}
\hline \multicolumn{3}{|c|}{ Table 4 } \\
\hline \multicolumn{3}{|c|}{ NEGAFF Negative Affect - yes or no } \\
\hline & Frequency & Valid Percent \\
\hline No & 85 & 44.97 \\
\hline Yes & 104 & 55.03 \\
\hline
\end{tabular}




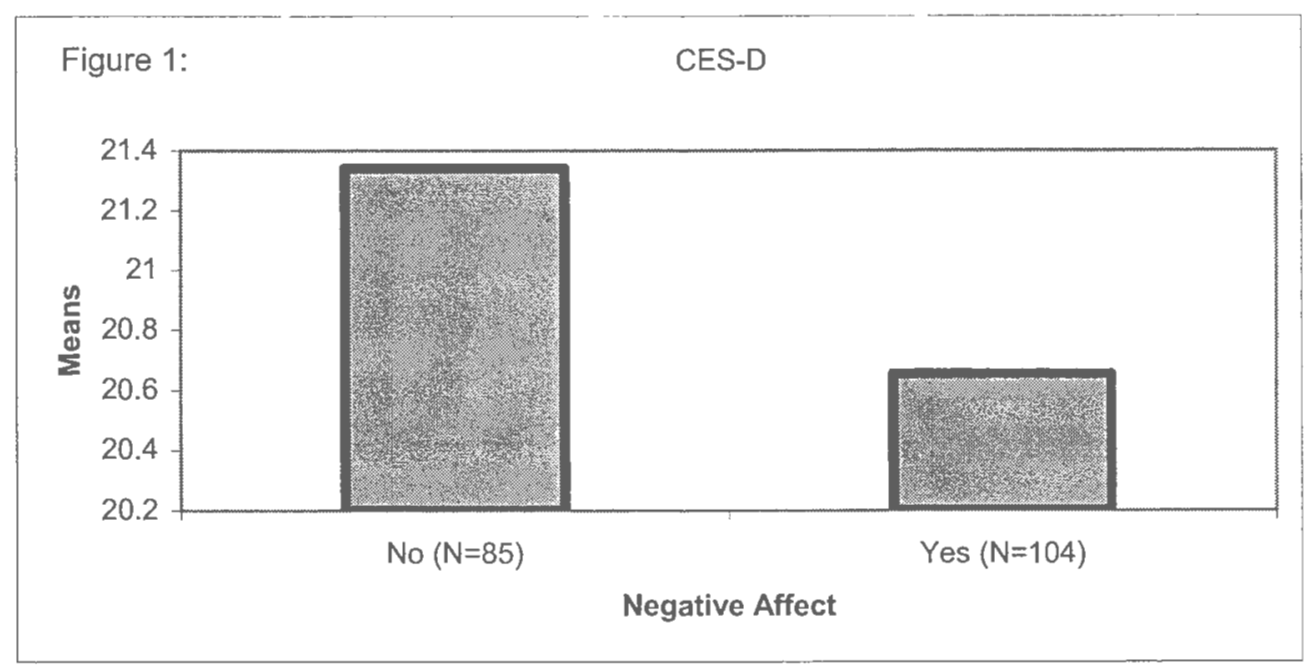



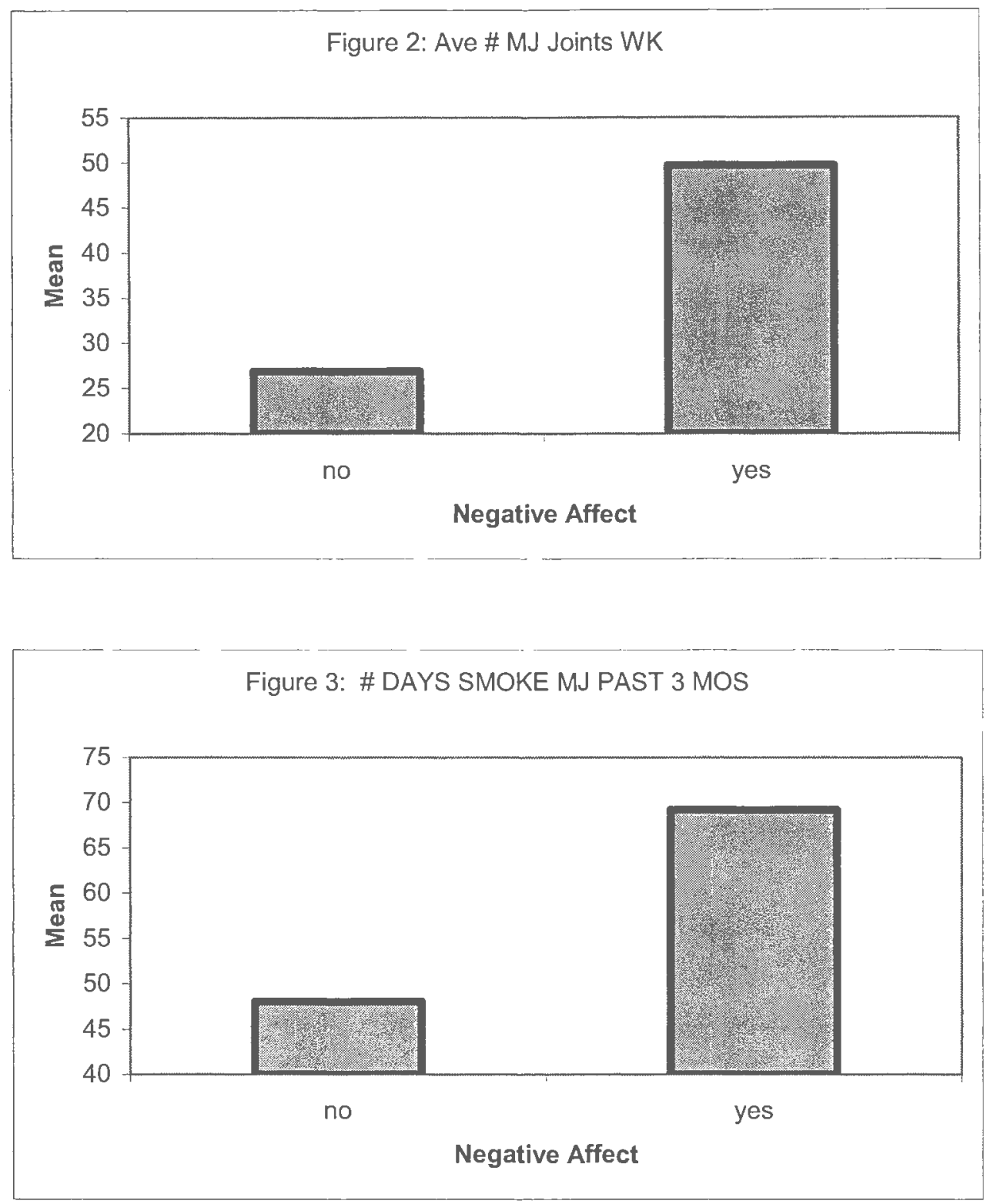

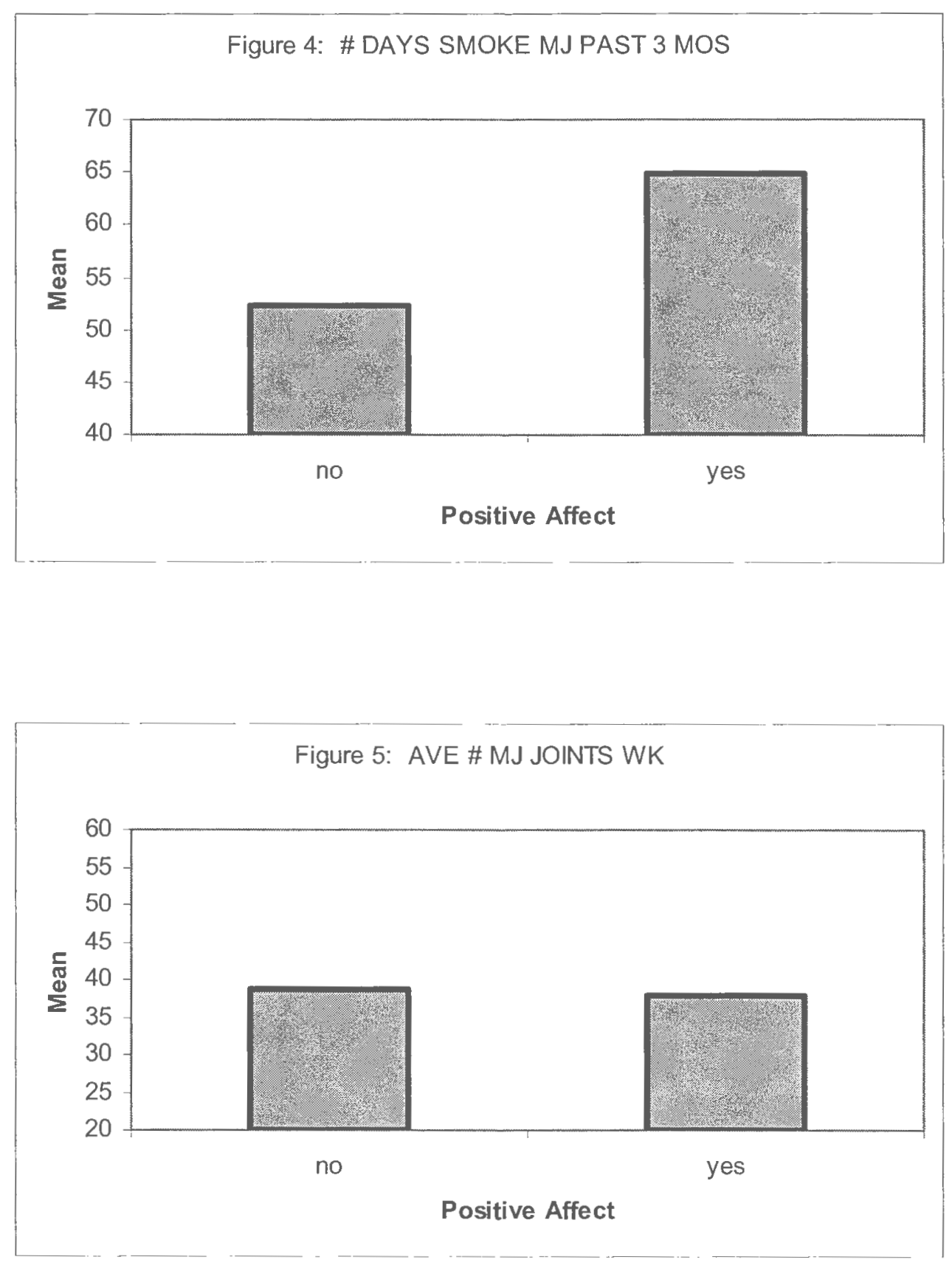
Appendix A

\section{Contents:}

1. Parent Consent

2. Teen Assent

3. Teen Consent (ages 18-19; emancipated minors) 


\section{PARENT/GUARDIAN CONSENT}

\section{Dear Parent or Legal Guardian:}

Teens of the Rhode Island Training School for Youth (RITS) are being asked to take part in a Brown University research project. This form will be explained to you and you can also read the form yourself. Please ask any questions you might have. Then if you decide to allow your teen to be in the project, please sign this form in front of the Researcher and a witness.

\section{Nature and Purpose of the Project}

We are trying to determine if talking to teenagers at the RITS will increase their treatment participation and reduce or prevent risky health behaviors (like being injured or drinking alcohol) after release.

\section{Explanation of Procedures}

RITS teens will be asked to complete several questionnaires regarding their education, health behaviors (for example, accidental injuries and fighting), misbehaviors, feelings of sadness, and treatment participation. All questionnaires will be read to teens. These questionnaires will take approximately 2 hours on one day. Your teen will be given breaks with snacks the questionnaires. Teens will be randomly assigned (using a procedure like flipping a coin) to one of two treatment groups. We do not know whether one of these treatments is more helpful than the other. Half of the teens will be trained in meditation and relaxation to reduce stress. Teens in the other half will discuss risky health behaviors. Your teen will receive about 2 hours of treatment on one day. Snack breaks will be provided during the session and after completing the treatment session, your teen will receive a larger food item (such as McDonalds, pizza, or Chinese food). Teens will be interviewed two more times while in the RITS about attitudes towards treatment and towards various health behaviors (like using marijuana or alcohol). Teens who received training in meditation and relaxation will receive further training in these skills. Again, the remaining half of teens will continue discussing the negative impact of risky health behaviors on their lives. Each of these two sessions will be about 90 minutes. Again, teens will receive snacks and a larger food item. RITS staff will rate how active teens are in treatment. Project staff will review the teen's record to determine, for example, number of prior incarcerations. Teens will be contacted at 3 months after release from the RITS. At this time they will again complete several questionnaires regarding health behaviors and misbehaviors, and all questionnaires will be read to teens. They will also be asked to provide a urine specimen. This final contact will last for about 2 hours and your teen will receive a snack break as well as a gift certificate at the end. This is a $\$ 50$ gift certificate for movies, groceries, music or clothes. Should your teen complete this follow-up within one week of its scheduled date, he/she will receive a $\$ 10$ bonus gift certificate. Questions about this study should be directed to Dr. Lynda Stein at (401) 444-1824. 
We need to know whether our intervention was helpful. Therefore, we will make every effort to contact your teen for the one time follow-up interview at 3 months after release. Your teen will be asked to give information on two people (family or friends) who are likely to know where he/she is after release. We will use these two people only if other ways of contacting your teen don't work. We may ask family, a case-worker, or probation officer where the teen is, but at no time will we share any information about your teen. No one will know what the study is about and no information about your teen will be shared with other people.

\section{Discomforts and Risks}

The risks in this study are considered minimal. The questionnaires used in this study are commonly used in research and clinical practice. Teens may experience some emotional discomfort in discussing their health behaviors.

\section{Benefits}

By answering these questions, teens have the opportunity to learn more about the dangers of risky health behaviors. This may prevent or reduce the chances that they are injured after release. This may reduce the chances that they will be in trouble with the law again.

\section{Alternative Treatment}

If you decide that your teen should not participate in this study (or if your teen decides not to participate), we offer no alternative treatments.

\section{Confidentiality}

Each teen's records from the project will be treated as confidential and private records. Your teen's name will not be on the questionnaires. Records will be kept in a locked filing cabinet at Brown University. Only researchers will have access to the information provided by teens. No information will be shared with other parties such as legal authorities, parents, school personnel, case-workers, parole officers, employers, or the RITS without the teen's approval. We have a Certificate of Confidentiality, granted by the Secretary of Health and Human Services (HHS). The Secretary does not encourage or discourage this research. The Certificate does not apply if HHS wishes to examine the researchers or research project activities. The Certificate is a legal document to protect information that the teens provide from being shared in any Federal, State or local civil, criminal, administrative, legislative, or other proceedings. The purpose of the Certificate is to protect researchers from being forced to release information on teens. Instances when information will not be kept confidential involve reports of escape plans, child abuse, or threats to harm self or others. While the results of the research project will probably be shared with other people and may be published in scientific reports, the names of teens and the fact that any particular teen was in the project will be kept confidential by the researchers. 


\section{Refusal/Withdrawal}

The decision whether to allow RITS teens to be in the study is entirely up to parents/legal guardians and RITS teens. Participation is voluntary. There will be no effect on the care provided by the RITS if teens refuse to participate or if parents/legal guardians refuse to let teens participate. There will be no effect on the care provided by the RITS if teens drop out of the project or if teens are withdrawn by parents/legal guardians.

\section{Medical Treatment/Compensation in Case of Injury}

We do not expect any unusual risk in this research project. Risks involved in this project are considered minimal and should be similar to those experienced in daily life or the performance of routine physical or psychological tests.

\section{Rights and Complaints}

If you or your teen have any questions about a teen's participation in this project, or would like more information about the rules for research projects, or the rights of people who take part in research, please contact Dorinda Williams at Brown University, telephone number (401) 863-1803.

I ACKNOWLEDGE THAT THE ABOVE EXPLANATION OF THIS PROJECT HAS BEEN READ TO ME AND THAT ALL OF MY QUESTIONS HAVE BEEN SATISFACTORILY ANSWERED. I GIVE MY PERMISSION FOR MY TEENAGER TO PARTICIPATE IN THIS RESEARCH PROJECT, AND I WILL RECEIVE A COPY OF THIS FORM.

Date

I ACKNOWLEDGE THE PROCESS AND/OR SIGNATURE OR STATEMENT SET FORTH ABOVE.

Witness Signature Date

I CERTIFY THAT I HAVE EXPLAINED FULLY TO THE ABOVE PARENT/GUARDIAN THE NATURE AND PURPOSE, PROCEDURES, AND THE POSSIBLE RISK AND POTENTIAL BENEFITS OF THIS RESEARCH PROJECT. 


\section{ASSENT-N}

Teens at the Rhode Island Training School for Youth (RITS) are being asked to take part in a Brown University research project. This form will be explained to you, and you will also have an opportunity to read the form to yourself and ask questions. If you decide to fill out the brief questionnaire, please sign this form in front of the researcher.

\section{Nature and Purpose of the Brief Questionnaire}

You decided not to participate in a Brown University study on reducing alcohol and marijuana use in RITS teens. Instead you will be asked to fill out a brief, anonymous questionnaire containing background information (like your age), and a few items concerning your alcohol and marijuana use and the number of times you have been incarcerated. This is so we can have a better sense of the people who come through the RITS and how we can help them with our research.

\section{Explanation of Procedures}

You will be asked to complete just one brief questionnaire regarding use of substances like alcohol and marijuana, and reasons why you did not want to be in the research project. We will read the questionnaire to you. It is only one page in length and will take just a few minutes of your time. Questions about this study should be directed to Dr. Lynda Stein at (401) 444-1824.

\section{Benefits/Discomforts and Risks/Treatment Alternatives}

There are no known benefits to filling out this questionnaire. The risks in filling out this questionnaire are considered minimal. The questions asked are commonly used in research and when you see a doctor. If you decide not to fill out this questionnaire (or if your parent/guardian decides you should not fill it out), we offer no alternative questionnaires to complete.

\section{Confidentiality}

This questionnaire will be treated as confidential and private. Your name will not be on this questionnaire. This brief questionnaire will be kept in a locked filing cabinet at Brown University. Only researchers will have access to the information you provide. No information will be shared with others such as legal authorities, parents, school personnel, case-workers, parole officers, employers, or the RITS without your written approval. We have a Certificate of Confidentiality, granted by the Secretary of Health and Human Services (HHS). The Secretary does not encourage or discourage this research. The Certificate does not apply if HHS wishes to examine the researchers or research project activities. The Certificate is a legal document to protect information that you give us from being shared in any Federal, State or local civil, criminal, administrative, legislative, or other proceedings. The purpose of the Certificate is to protect researchers from being forced to release information about teens. All 
information will be confidential and private unless it involves reports of child abuse, escape plans, or threats to harm yourself or others. The results of the research project will probably be published, but your name and the fact that you were in the project will be kept confidential by the researchers.

\section{Refusal/Withdrawal}

The decision whether you fill out the brief questionnaire is entirely up to your parent/legal guardian and you. Participation is voluntary. The care you receive at the RITS will not change if you decide not to complete the brief questionnaire or if your parent/legal guardian does not want you to complete the brief questionnaire.

6. Medical Treatment/Compensation in Case of Injury

We do not expect any unusual risk in completing this brief questionnaire. Risks involved are considered minimal and should be similar to those experienced in daily life or the performance of routine physical or psychological tests.

7. Rights and Complaints

If you have any questions about filling out the brief questionnaire, or would like more information about the rules for research projects, or the rights of people who take part in research, please contact Dorinda Williams at Brown University, telephone number (401) 863-1803.

I ACKNOWLEDGE THAT THE ABOVE EXPLANATION OF THE BRIEF QUESTIONNAIRE HAS BEEN READ TO ME AND THAT ALL OF MY QUESTIONS HAVE BEEN SATISFACTORILY ANSWERED. I AGREE TO FILL OUT THE BRIEF QUESTIONNAIRE, AND I WILL RECEIVE A COPY OF THIS FORM.

Participant Signature

Date

I CERTIFY THAT I HAVE EXPLAINED FULLY TO THE ABOVE PARTICIPANT THE NATURE AND PURPOSE, PROCEDURES, AND THE POSSIBLE RISK AND POTENTIAL BENEFITS OF FILLING OUT THE BRIEF QUESTIONNAIRE. 


\section{TEEN CONSENT}

(18-19; E.M.)

Teens of the Rhode Island Training School for Youth (RITS) are being asked to take part in a Brown University research project. This form will be explained to you, and you will also have an opportunity to read the form to yourself and ask any questions you may have. If you decide to be in the project, please sign this form in front of the researcher.

\section{Nature and Purpose of the Project}

We are trying to determine if talking to teenagers like you will increase treatment participation and reduce or prevent substance use and negative things that can happen when using substances (for example, being injured when drinking alcohol).

\section{Explanation of Procedures}

You will be asked to complete several questionnaires regarding your education, use of substances like marijuana and alcohol, misbehaviors and injuries, feelings of sadness, and treatment participation. All questionnaires will be read to you. These questionnaires will take approximately 2 hours on one day. You will be given breaks with snacks during the session. Then you will be assigned (using a procedure like flipping a coin) to one of two treatment groups, and we do not know whether one of these groups is more helpful than the other. You may be trained in meditation and relaxation to reduce stress. Or you may be asked to discuss your use of alcohol and marijuana and what happens when you use these substances. You will receive approximately 2 hours of treatment on one day. Snack breaks will be provided during this session and after completing the treatment, you will receive a larger food item (such as McDonalds, pizza, or Chinese food). You will be interviewed two more times while in the RITS about attitudes towards treatment and towards use of alcohol or marijuana. If you received training in meditation and relaxation you will receive further training in these skills. Or you may continue discussing experiences with alcohol and marijuana. Each of these two sessions will be approximately 90 minutes. Again, you will receive snacks and a larger food item. RITS staff will rate how active you are in treatment. Project staff will review records to determine, for example, number of prior incarcerations. Finally, we will contact you 3 months after release from the RITS. At this time we will again complete several questionnaires regarding use of substances like alcohol and marijuana. All questionnaires will be read to you. You will be asked to provide a urine specimen. This final contact will last for approximately 2 hours and you will receive a snack break as well as a gift certificate at the end. This is a $\$ 50$ gift certificate for movies, groceries, music or clothes. Should you complete this follow-up within one week of its scheduled date, you will receive a $\$ 10$ bonus gift certificate. Questions about this study should be directed to Dr. Lynda Stein at (401) 444-1824. 
We need to know whether our intervention was helpful. Therefore, we will make every effort to contact you for the one time follow-up interview at 3 months after release. You'll be asked to give information on two people (family or friends) who are likely to know where you are after release. We will use these two people only if other ways of contacting you don't work. We may ask family, a case-worker, or parole officer where you are, but at no time will we share any information you gave us. No one will know what the study is about and no information you give us will be shared with other people.

\section{Discomforts and Risks}

The risks in this study are considered minimal. The questions we ask in this study are commonly used in research and when you see a doctor. You may feel a little uncomfortable discussing substance use and some of your behaviors.

\section{Benefits}

By answering these questions, you have the opportunity to learn more about yourself and others who use alcohol or marijuana. You may be able to lower the chances that you will have problems or injuries related to use of substances like alcohol or marijuana. You may be able to reduce the chances that you will be in trouble with the law again.

\section{Alternative Treatment}

If you decide that you should not participate in this study, we offer no alternative treatments.

\section{Confidentiality}

Records from the project will be treated as confidential and private. Your name will not go on the questionnaires. Records will be kept in a locked filing cabinet at Brown University. Only researchers will have access to the information you provide. No information will be shared with others such as legal authorities, parents, school personnel, case-workers, parole officers, employers, or the RITS without your written approval. We have a Certificate of Confidentiality, granted by the Secretary of Health and Human Services (HHS). The Secretary does not encourage or discourage this research. The Certificate does not apply if HHS wishes to examine the researchers or research project activities. The Certificate is a legal document to protect information that you give us from being shared in any Federal, State or local civil, criminal, administrative, legislative, or other proceedings. The purpose of the Certificate is to protect researchers from being forced to release information about teens. All information will be confidential and private unless it involves reports of child abuse, escape plans, or threats to harm yourself or others. The results of the research project will probably be published, but your name and the fact that you were in the project will be kept confidential by the researchers.

\section{Refusal/Withdrawal}

The decision whether you will be in the study is entirely up to you. Participation is voluntary. There will be no change in the care provided by the RITS if you decide 
not to be in the study. There will be no change in the care provided by the RITS if you drop out of the project later.

\section{Medical Treatment/Compensation in Case of Injury}

We do not expect any unusual risk in this research project. Risks involved in this project are considered minimal and should be similar to those experienced in daily life or the performance of routine physical or psychological tests.

9. $\quad$ Rights and Complaints

If you have any questions about your participation in this project, or would like more information about the rules for research projects, or the rights of people who take part in research, please contact Dorinda Williams at Brown University, telephone number (401) 863-1803.

I ACKNOWLEDGE THAT THE ABOVE EXPLANATION OF THIS PROJECT HAS BEEN READ TO ME AND THAT ALL OF MY QUESTIONS HAVE BEEN SATISFACTORILY ANSWERED. I AGREE TO PARTICIPATE, AND I WILL RECEIVE A COPY OF THIS FORM. THE NATURE AND PURPOSE, PROCEDURES, AND THE POSSIBLE RISK AND POTENTIAL BENEFITS OF THIS RESEARCH PROJECT. 


\section{Appendix B}

\section{Contents:}

1. Background Questionnaire

2. Brief Situational Confidence Questionnaire-Marijuana

3. Center for Epidemiological Studies Depression Scale

4. Marijuana Effects Expectancies Questionnaire-Brief

5. Substance Use Diagnosis for Marijuana Inventory

6. Timeline Followback-Marijuana 


\section{BGQ(Baseline)}

1. Ethnic/Racial background (Circle one):

$1=$ African-American 2 = Asian-American $3=$ Native-American $4=$ Caucasian $5=$ Hispanic $/$ Latino $\quad 6=$ Other

2. Gender: $1=$ Male $\quad 2=$ Female

3. Date of birth:

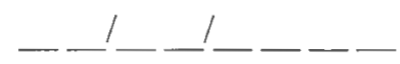

4. Mother or female caretaker's highest education:

$$
\begin{aligned}
& 1=\text { grade school (up to } 8^{\text {th }} \text { grade) } 5=\text { some college } \\
& 2=\text { some high school } \\
& 3=\text { graduated high school } \\
& 4=\text { GED }
\end{aligned}
$$

5. Father or male caretaker's highest education:

$$
\begin{aligned}
& 1=\text { grade school (up to } 8^{\text {th }} \text { grade) } \quad 5=\text { some college } \\
& 2=\text { some high school } \quad 6=\text { graduated college } \\
& 3 \text { = graduated high school } \\
& 4=\text { GED }
\end{aligned}
$$

6. Parent or caretaker on public assistance? $\quad 0=$ No $\quad 1=$ Yes

7. Father (biological) ever incarcerated or put in detention?

$$
0=\text { No } \quad 1=\text { Yes } \quad 2=\text { Unable to determine }
$$

8. Mother (biological) ever incarcerated or put in detention?

$$
0=\text { No } \quad 1=\text { Yes } \quad 2=\text { Unable to determine }
$$

9. Did your father (biological) ever have trouble with the following because of his alcohol or drug use? (Circle all that apply.)

$\begin{array}{clll}\text { family or friends } & 0=\text { No } & 1=\text { Yes } & 2=\text { Unable to determine } \\ \text { job } & 0=\text { No } & 1=\text { Yes } & 2=\text { Unable to determine } \\ \text { law } & 0=\text { No } & 1=\text { Yes } & 2=\text { Unable to determine }\end{array}$

10. Did your father (biological) ever get counseling, or go to treatment or AA/NA for his alcohol or drug use?

$$
0=\text { No } \quad 1=\text { Yes } \quad 2=\text { Unable to determine }
$$

11. Father (biological) with history of alcohol/drug abuse?

$$
0=\text { No } \quad 1=\text { Yes } \quad 2=\text { Unable to determine }
$$

12. Did your mother (biological) ever have trouble with the following because of her alcohol or drug use? (Circle all that apply.)

$\begin{array}{clll}\text { family or friends } & 0=\text { No } & 1=\text { Yes } & 2=\text { Unable to determine } \\ \text { job } & 0=\text { No } & 1=\text { Yes } & 2=\text { Unable to determine } \\ \text { law } & 0=\text { No } & 1=\text { Yes } & 2=\text { Unable to determine }\end{array}$


13. Did your mother (biological) ever get counseling, or go to treatment or AA/NA for her alcohol or drug use?

$$
0=\text { No } \quad 1=\text { Yes } \quad 2=\text { Unable to determine }
$$

14. Mother (biological) with history of alcohol/drug abuse?

$$
0=\text { No } \quad 1=\text { Yes } \quad 2=\text { Unable to determine }
$$

15. Before coming to the Rhode Island Training School, most free time was been spent with (circle one):

$$
\begin{aligned}
& 1=\text { alcohol or other drug (AOD) using peer(s) } \\
& 2=\text { non-AOD using peer(s) } \\
& 3=\text { AOD using family member(s) } \\
& 4=\text { non-AOD using family member(s) } \\
& 5=\text { AOD using care-taker(s) } \\
& 6=\text { non-AOD using care-taker(s) } \\
& 7=\text { alone }
\end{aligned}
$$

16. Prior to coming to the RITS, how many family members did you see at least once per week?

17. How many of them use alcohol or drugs at least once per week?

Did not see family once/wk $=-8$

18. About how many friends do you have?

19. About how many of them use alcohol or drugs at least once per month?

20. About how many of your friends have been arrested before?

21. Number of times previously in detention or incarcerated? times

22. Total length of time in both detention facilities and incarcerated (not counting current)? wks

23. About how many people your age do you think use:

marijuana out of 10

24. Most of the time, how do you get your marijuana?

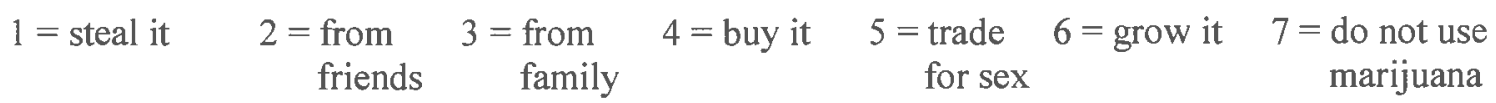

25. Number of days in the 12 months before coming to the RITS you have used:

Days used in past 12 months

marijuana 
26. How old were you when you first used the following?
marijuana:
years old
$1=$ Have not used

27. How old were you when you first got...?
high from marijuana:
years old
$1=$ Have not used

28. How old were you when you first got arrested?

years old.

Note for next questions: "Once per month or more" refers to a 3 month period or more; "once per week or more" refers to a 4 week period or more; and "daily" refers to a 5 day period or more.

29. How old were you when you began using marijuana...?

once per month or more once per week or more daily years old years old years old
$1=$ Never used once per month or more $1=$ Never used once per week or more $1=$ Never used once per day or more

30. How risky is it to your health to use marijuana regularly? (circle one)

$0=$ Not at all risky $\quad 1=$ Probably not risky

2 = May be risky

$3=$ Very risky 
Subj. No.

Date

\section{BSCQ-M}

Listed below are nine types of situations in which some people experience a problem with marijuana. Imagine yourself as you are right now in each of the following types of situations. Indicate how confident you are right now that you would be able to resist marijuana use in each situation. 0\% means you are "Not At All Confident" and 100\% means you are "Totally Confident."

\section{Right now how confident are you that you can resist marijuana use when ...}

1. ... you feel UNPLEASANT EMOTIONS (If you were depressed about things in general, if every thing were going badly for you)?

$\begin{array}{lcc}0 \% & 0 \% \\ \text { Not at all } & \text { Unsure } & \text { Totally } \\ \text { confident } & & \text { confident }\end{array}$

2. ...you feel PHYSICAL DISCOMFORT (If you were to have trouble sleeping, or felt jumpy and physically tense)?

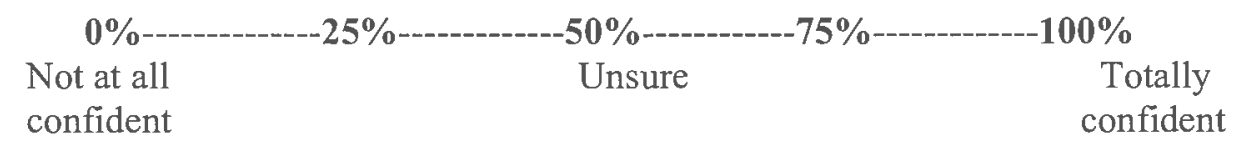

3. ... you feel PLEASANT EMOTIONS (If something good happened and you felt like celebrating, if everything were going well)?

0\%-1
$\begin{aligned} & \text { Not at all } \\ & \text { confident }\end{aligned}$
Unsure

4. ...you feel like TESTING CONTROL OVER YOUR USE OF MARIJUANA (If you started to believe that marijuana wasn't a problem for you, if you felt confident that you could handle using marijuana)?

$\begin{array}{lcc}0 \% & 0 \\ \text { Not at all } & \text { Unsure } & \text { Totally } \\ \text { confident } & & \text { confident }\end{array}$

5. ...you feel URGES AND TEMPTATIONS (If you suddenly had an urge to use marijuana, if you were in a situation where you often used marijuana before)?

\begin{tabular}{|c|c|}
\hline \multicolumn{2}{|c|}{ 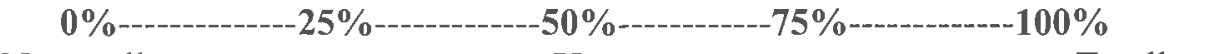 } \\
\hline $\begin{array}{l}\text { Not at all } \\
\text { confident }\end{array}$ & Unsure \\
\hline
\end{tabular}


Right now how confident are you that you can resist marijuana use when ...

6. ...you have CONFLICT WITH OTHERS (If you had an argument with a friend, if you were not getting along well with others at work/school)?

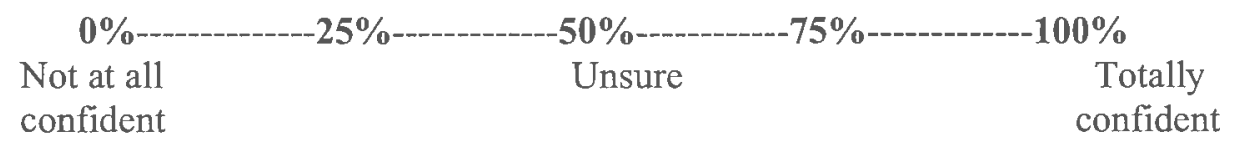

7. ...you feel SOCIAL PRESSURE TO USE (If someone were to pressure you to "be a good sport" and use marijuana with him/her, if you were invited to someone's home and she/he offered you a some marijuana)?

\begin{tabular}{|c|c|}
\hline \multicolumn{2}{|c|}{ 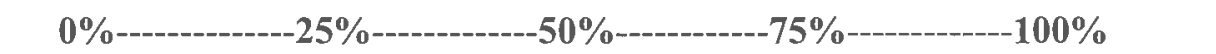 } \\
\hline $\begin{array}{l}\text { Not at all } \\
\text { confident }\end{array}$ & Unsure \\
\hline
\end{tabular}

8. ...you have PLEASANT TIMES WITH OTHERS (If you wanted to celebrate with a friend, if you were enjoying yourself at a party and wanted to feel even better).

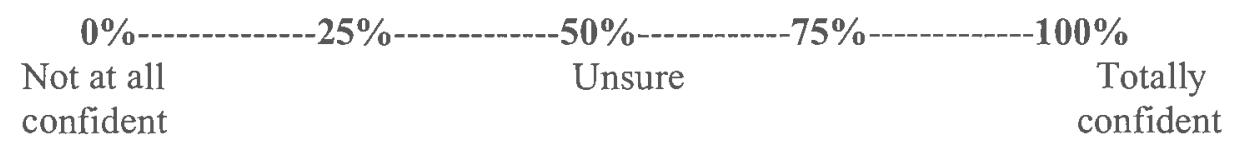

9. ...you have SCHOOL/WORK PROBLEMS (If you felt like you couldn't do your work or school assignments, if you didn't like your job or school work).

$\begin{array}{lcc}0 \% & 0 \\ \text { Not at all } & \text { Unsure } & \text { Totally } \\ \text { confident } & & \text { confident }\end{array}$




\section{CES-D}

For each of the following statements below, please indicate how often you have felt this way in the past week:

$0=$ Rarely or none of the time ( 0 days $)$

$1=$ Some or little of the time $(1-2$ days $)$

$2=$ Occasionally or a moderate amount of time ( $3-4$ days)

$3=$ Most or all of the time $(5-7$ days $)$

1. I was bothered by things that don't usually bother me.

2. I did not feel like eating; my appetite was poor.

3. I felt that I could not shake off the blues even with help from family or friends.

4. I felt that I was just as good as other people.

5. I had trouble keeping my mind on what I was doing.

6. I felt depressed.

7. I felt that everything that I did was an effort.

8. I felt hopeful about the future.

9. I thought my life had been a failure.

10. I felt fearful.

11. My sleep was restless.

12. I was happy.

13. I talked less than usual.

14. I felt lonely.

15. People were unfriendly.

16. I enjoyed life.

17. I had crying spells.

18. I felt sad.

19. I felt that people dislike me.

20. I could not "get going" 


\section{MEEQ-B}

Subj. No.

Date

The following pages contain statements about the effects of marijuana. Answer each statement according to your own personal thoughts, feelings, and beliefs about marijuana. We're interested in what you think about marijuana, not what others might think. Whether or not you've had actual marijuana experience, you should answer in terms of how you think marijuana affects the typical or average user.

\section{Answer according to how much you agree or disagree with each question.}

1. Marijuana makes it harder to think and do things (harder to concentrate or understand; slows you down when you move).

$\begin{array}{llccc}1 & 2 & 3 & 4 & 5 \\ \text { Disagree } & \text { Disagree } & \text { Uncertain } & \text { Agree } & \text { Agree } \\ \text { Strongly } & \text { Somewhat } & & \text { Somewhat } & \text { Strongly }\end{array}$

2. Marijuana helps a person relax and feel less tense (helps you unwind and feel calm).

$\begin{array}{llccc}1 & 2 & 3 & 4 & 5 \\ \text { Disagree } & \text { Disagree } & \text { Uncertain } & \text { Agree } & \text { Agree } \\ \text { Strongly } & \text { Somewhat } & & \text { Somewhat } & \text { Strongly }\end{array}$

3. Marijuana helps people get along better with others and it can help you feel more sexual (talk more; feel more romantic).

$\begin{array}{llccc}1 & 2 & 3 & 4 & 5 \\ \text { Disagree } & \text { Disagree } & \text { Uncertain } & \text { Agree } & \text { Agree } \\ \text { Strongly } & \text { Somewhat } & & \text { Somewhat } & \text { Strongly }\end{array}$

4. Marijuana makes a person feel more creative and perceive things differently (music sounds different; things seem more interesting).

\begin{tabular}{|c|c|c|c|c|}
\hline 1 & 2 & 3 & 4 & 5 \\
\hline Disagree & Disagree & Uncertain & Agree & Agree \\
\hline Strongly & Somewhat & & Somewhat & Strongly \\
\hline
\end{tabular}


5. Marijuana generally has bad effects on a person (you become angry or careless; after feeling high you feel down).

$\begin{array}{llccc}1 & 2 & 3 & 4 & 5 \\ \text { Disagree } & \text { Disagree } & \text { Uncertain } & \text { Agree } & \text { Agree } \\ \text { Strongly } & \text { Somewhat } & & \text { Somewhat } & \text { Strongly }\end{array}$

6. Marijuana has effects on a person's body and gives a person cravings (get the munchies/hungry; have a dry mouth; hard to stop laughing).

$\begin{array}{llccc}1 & 2 & 3 & 4 & 5 \\ \text { Disagree } & \text { Disagree } & \text { Uncertain } & \text { Agree } & \text { Agree } \\ \text { Strongly } & \text { Somewhat } & & \text { Somewhat } & \text { Strongly }\end{array}$


Subj. No.

Date

\section{Marijuana Dependence Dx Checklist}

Note to Staff: "Last 12 months" means last 12 months before admission.

Last 12 mo. Ever

1. a. Have you had to use a lot more marijuana than you once used to, to get as high as you want?

b. When you smoke/eat your usual amount, do

$$
0=\mathrm{N} \quad 1=\mathrm{Y} \quad 0=\mathrm{N} \quad 1=\mathrm{Y}
$$

OR you get the same effect as you used to? (If answer is "Yes," mark N; if answer is "No," mark Y.)

$$
0=\mathrm{N} \quad 1=\mathrm{Y} \quad 0=\mathrm{N} \quad 1=\mathrm{Y}
$$

(Check here if symptom present) Tolerance:

2. a. Have you often used more marijuana than you planned?

b. Have you used marijuana over a longer period of time that you planned?

$$
0=\mathrm{N} \quad 1=\mathrm{Y} \quad 0=\mathrm{N} \quad 1=\mathrm{Y}
$$

OR

$$
0=\mathrm{N} \quad 1=\mathrm{Y} \quad 0=\mathrm{N} \quad 1=\mathrm{Y}
$$

3. a. Have you often had a strong desire to cut down $0=\mathrm{N} \quad 1=\mathrm{Y}$ or stop using marijuana?

b. Have you ever tried to cut down or stop using marijuana, but couldn't?

$$
0=N \quad 1=Y
$$

OR

$$
0=\mathrm{N} \quad 1=\mathrm{Y} \quad 0=\mathrm{N} \quad 1=\mathrm{Y}
$$

(Check here if symptom present)

$$
0=\mathrm{N} \quad 1=\mathrm{Y}
$$
get marijuana?

b. Have you spent a great deal of time using marijuana? $0=\mathrm{N} \quad 1=\mathrm{Y}$

$$
0=\mathrm{N} \quad 1=\mathrm{Y}
$$

OR

(Check here if symptom present) 
5. a. Has your marijuana use interfered with your spare time activities and hobbies?

$$
0=\mathrm{N} 1=\mathrm{Y} \quad 0=\mathrm{N} \quad 1=\mathrm{Y}
$$

OR

b. Has your marijuana use led you to spend less time than you should at work or school or to quit a job or school?

OR

c. Has your marijuana use gotten in the way of doing things with your friends?

$$
0=N \quad 1=Y \quad 0=N \quad 1=Y
$$

OR

d. Has your marijuana use interfered with your social life?

$$
0=\mathrm{N} 1=\mathrm{Y} \quad 0=\mathrm{N} 1=\mathrm{Y}
$$

(Check here if symptom present)

6. a. Has your marijuana use caused serious physical $\quad 0=\mathrm{N} \quad 1=\mathrm{Y} \quad 0=\mathrm{N} \quad 1=\mathrm{Y}$ problems that have lasted or occurred again and again?

AND

b. Have you continued to use marijuana despite knowing that marijuana causes physical problems for you?

$$
0=\mathrm{N} \quad 1=\mathrm{Y} \quad 0=\mathrm{N} 1=\mathrm{Y}
$$

OR

c. Has your marijuana use caused serious psychological $0=\mathrm{N} \quad 1=\mathrm{Y} \quad 0=\mathrm{N} \quad 1=\mathrm{Y}$ problems that have lasted or occurred again and again?

d. Have you continued to use marijuana despite knowing that marijuana causes psychological problems for you? $\quad 0=\mathrm{N} \quad 1=\mathrm{Y} \quad 0=\mathrm{N} \quad 1=\mathrm{Y}$

(Check here if symptom present)

Have at least 3 of these symptoms (items 1-6) been present in the last 12 -months before admission? $N$ (cont. w/ abuse) $\quad \mathrm{Y}($ dep.) 


\section{Marijuana Abuse Dx Checklist}

Note to Staff: "Last 12 months" means last 12 months before admission.

Last 12 mo. Ever

1. a. Has your marijuana use interfered with your

$$
0=\mathrm{N} 1=\mathrm{Y} \quad 0=\mathrm{N} 1=\mathrm{Y}
$$
obligations at home or had a harmful effect on your home life?

OR

b. Has your marijuana use led you to miss work/school, $0=\mathrm{N} 1=\mathrm{Y} \quad 0=\mathrm{N} 1=\mathrm{Y}$ negatively affected your performance at work/school, or to quit or be fired from a job/school?

(Check here if symptom present)

2. Have you used marijuana when it was physically $\quad 0=\mathrm{N} \quad 1=\mathrm{Y} \quad 0=\mathrm{N} \quad 1=\mathrm{Y}$ dangerous to do so or when doing things that could lead to injury such as driving, using machinery, or sports?

(Check here if symptom present)

3. Has your marijuana use caused two or more legal problems or made any legal problems worse?

$$
0=\mathrm{N} \quad 1=\mathrm{Y} \quad 0=\mathrm{N} 1=\mathrm{Y}
$$

(Check here if symptom present)

4. a. Has your marijuana use caused you to have problems again and again with your friends or family (such as fights or arguments)?

$$
0=\mathrm{N} 1=\mathrm{Y} \quad 0=\mathrm{N} 1=\mathrm{Y}
$$

OR

b. Has your marijuana use caused lasting problems with your friendships or family?

$$
0=\mathrm{N} 1=\mathrm{Y} \quad 0=\mathrm{N} 1=\mathrm{Y}
$$

AND

c. Have you continued to use marijuana despite knowing marijuana causes these problems for you?

$$
0=\mathrm{N} 1=\mathrm{Y} \quad 0=\mathrm{N} \quad 1=\mathrm{Y}
$$

(Check here if symptom present)

One (or more) symptoms present in the last 12 months before admission?

$$
\mathrm{N}(\text { no } D x) \quad \mathrm{Y} \text { (abuse) }
$$


Final Diagnostic Category-Select appropriate category 0-3

$0 \quad$ No marijuana diagnosis

1 Marijuana Abuse

2 Marijuana Dependence without tolerance

3 Marijuana Dependence with tolerance

Number of dependence symptoms checked

Age at onset of marijuana dependence. 
Baseline Follow-Back Example, Day 1 to Day 15

ID

Detention Date

$\begin{array}{lcll}\text { Key: } & & & \\ \text { Don't Know } & -9 & \text { Community } & 1 \\ \text { Yes, Unsure } & 99 & \text { Controlled } & 2 \\ \text { No Use } & 0 & \\ 1 \text { Hit }(\mathrm{J}) & .1 & \end{array}$

Coding: Day 1 is DETENTION DATE. Day 91 is furthest date

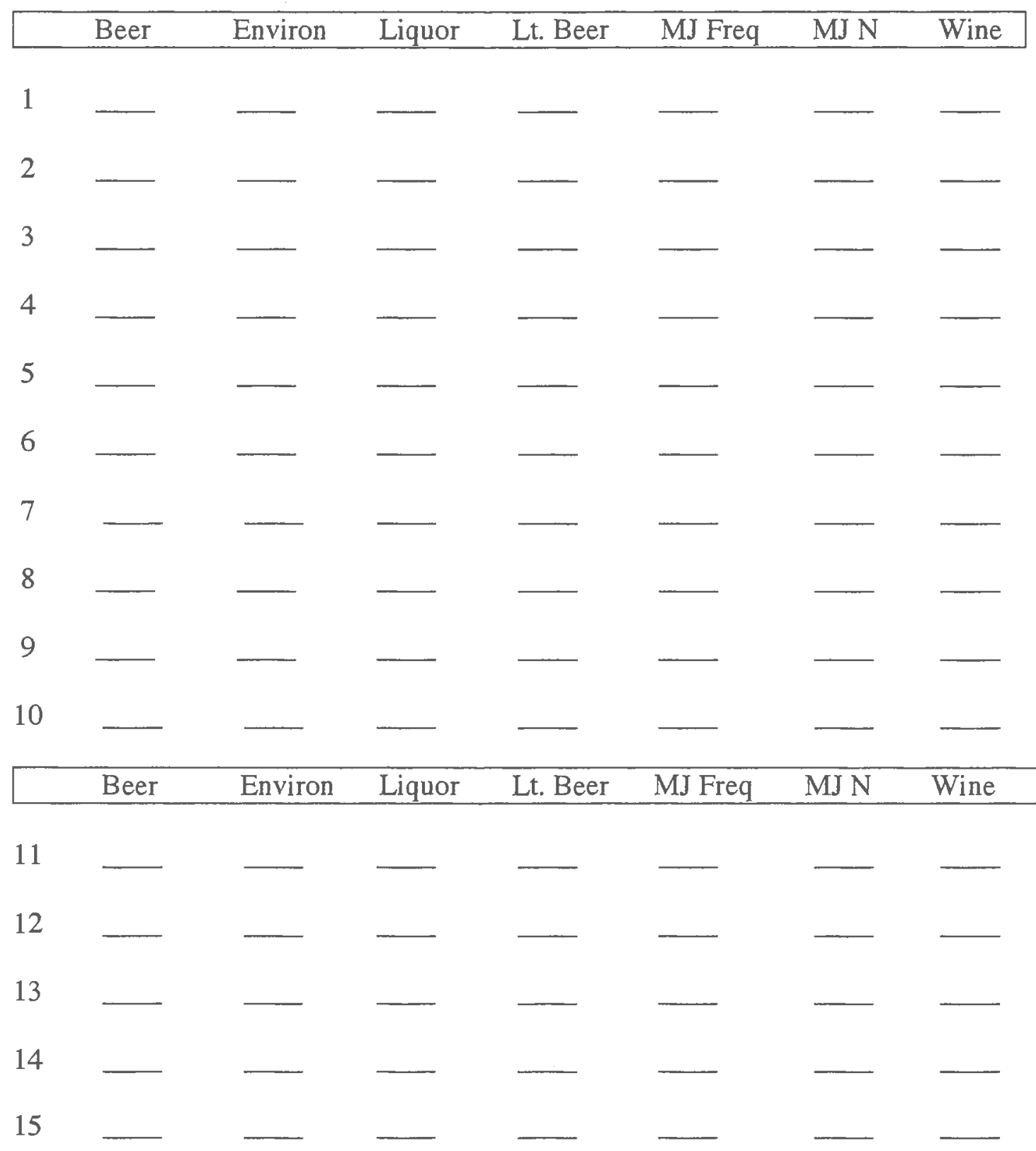




\section{Bibliography}

Aharonovich, E., Nguyen, H. T., \& Nunes, E. V. (2001). Anger and depressive states among treatment-seeking drug abusers: Testing the psychopharmacological specificity hypothesis. American Journal of the Addictions, 10(4), 327-334.

Arseneault, L., Moffitt, T. E., Caspi, A., Taylor, P. J., \& Silva, P. A. (2000). Mental disorders and violence in a total birth cohort: results from the Dunedin Study. Archives of General Psychiatry, 57, 979-986.

Babor, T. F., Webb, C., Burleson, J. A., \& Kaminer, Y. (2002). Subtypes for classifying adolescents with marijuana use disorders: Construct validity and clinical implications. Addiction, 97, 58-69.

Bailey, S. L., \& Hubbard, R. L. (1990). Developmental variation in the context of marijuana initiation among adolescents. Journal of Health and Social Behavior, 31, 58-70.

Barlow, J. H., \& Wright, C. C. (1998). Dimensions of the Center of Epidemiological Studies-Depression Scale for people with arthritis from the UK. Psychological Reports, 83(3), 915-919.

Bloom, B., Owen, B., Deschenes, E. P., \& Rosenbaum, J. (2002). Moving toward just for female juvenile offenders in the new millennium. Journal of Contemporary Criminal Justice, 18(1), 37-56.

Breslin, F. S., Sobell, L. C., Sobell, M. G., \& Agrawal, S. (2000). A comparison of a brief and a long version of the Situational Confidence Questionnaire. Behavioral Research Therapy, 38, 1211-1220.

Brook, J. S., Brook, D. W., DeLaRosa, M., Duque, L. F., Rodriguez, E., Montoya, I. D., \& Whiteman, M. (1998). Pathways to marijuana use among adolescents: Cultural/ecological, family, peer, and personality influences. Child and Adolescent Psychiatry, 37(7), 759-766.

Bulik, C. M., Prescott, C. A., \& Kendler, K. S. (2001). Features of childhood sexual abuse and the development of psychiatric and substance use disorders. British Journal of Psychiatry, 179, 444-449.

Bureau of Justice Statistics. (1999, January). Substance abuse and treatment: State and federal prisoners, 1997 (NCJ 172871). Washington, DC: U.S. Department of Justice, National Institute of Justice.

California Department of Corrections (1999). Overview of Substance Abuse Programs, Office of Substance Abuse Programs. 
Carpenter, J. S., Andryowski, M. A., Wilson, J., Hall, L. A., Rayens, M. K., Sachs, B., \& Cunningham, L. L.. (1998) Psychometrics for two short forms of the Center for Epidemiologic Studies-Depression Scale. Issues in Mental Health Nursing, 19(5), 481-494.

Carvalho, V., Pinsky, I., DeSouza, E., \& Silva, R. (1995). Drug and alcohol use and family characteristics: A study among Brazilian high school students. Addiction, $90,65-72$.

Chapman, R. A. (2006). Becoming a practitioner of cognitive behavioral therapy. In The clinical use of hypnosis in cognitive behavior therapy: A practitioner's casebook (pp. 333-340). New York, NY: Springer Publishing Company.

Chassin, L., Curran, P., Hussong, A., \& Colder, C. (1996). The relations of parent alcoholism to adolescent substance use: A longitudinal follow-up study. Journal of Abnormal Psychology, 105, 70-80.

Chassin, L., Pillow, D. R., Curran, P. J., Molina, B., \& Barrera, M. (1993). Relation of parental alcoholism to early adolescent substance use: A test of three mediating mechanisms. Journal of Abnormal Psychology, 102, 3-19.

Comeau, N., Stewart, S. H., \& Loba, P. (2001). The relations of trait anxiety, anxiety sensitivity, and sensation seeking to adolescents' motivations for alcohol, cigarettes, and marijuana use. Addictive Behaviors, 26, 803-825.

Connors, G. J., Watson, D. W., \& Maisto, M. B. (1985). Influence of subject and interviewer characteristics on the reliability of young adults' self-reports of drinking. Journal of Psychopathology and Behavioral Assessment, 7, 365-374.

Dennis, M., Titus, J. C., Diamond, G., Donaldson, J., Godley, S. H., Tims, F. M., et al. (2002). The Cannabis Youth Treatment (CYT) experiment: Rationale, study design and analysis plans. Addiction, 97 (Suppl. 1), 16-34.

Dembo, R., Schmiedler, J., Chin Sue, C., Borden, P., \& Manning, D. (1995). Gender differences in service needs among youths entering a juvenile assessment center. Journal of Correctional Health Care, 2(2), 191-217.

Dryfoos, J. G. (1990). Adolescents at risk: Prevalence and prevention. New York, NY: Oxford.

Dube, S. R., Felitti, V. J., Dong, M., Chapman, D. P., Giles, W. H., \& Anda, R. (2003). Childhood abuse, neglect, and household dysfunction and the risk of illicit drug use: The adverse childhood experiences study. Pediatrics, 111, 564-572. 
Epstein, R. A., Jr. (2004). Inpatient and residential treatment effects for children and adolescents: A review and critique. Child and Adolescent Psychiatric Clinics of North America, 13(2), 411-428.

Farrell, M., Danish, S. J., \& Howard, C. W. (1992). Relationship between drug use and other problem behaviors in urban adolescents. Journal of Consulting and Clinical Psychology, 60, 705-712.

Farrow, J. A, \& French J. (1986). The drug abuse-delinquency connection revisited. Adolescence, 21, 951-960.

Fergusson, D. M., Horwood, L. J., \& Lynskey, M. T. (1996). Childhood sexual abuse and psychiatric disorders in young adulthood: II. Psychiatric outcomes of childhood sexual abuse. Child \& Adolescent Psychiatry, 35(10), 1365-1374.

Fondacaro K. M., \& Holt, J. C. (1999). Psychological impact of childhood sexual abuse on male inmates: The importance of perception. Child Abuse \& Neglect, 23(4), 361-399.

Gorman, D. M., \& Derzon, J. H. (2002). Behavioral traits and marijuana use and abuse A meta-analysis of longitudinal studies. Addictive Behaviors, 27, 193206.

Green, B., Kavanagh, D. J., \& Young, R. (2004). Reasons for cannibis use in men with and without psychosis. Drug and Alcohol Review, 23, 445-453.

Grietens, H., \& Hellinckx, W. (2004). Evaluating effects of residential treatment for juvenile offenders by statistical metaanalysis: A review. Aggression and Violent Behavior, 9(4), 401-415.

Hall, W., Johnston, L., \& Donnelly, N. (1999). Epidemiology of cannabis use. In R. (Eds.), The Health Effects of Cannabis (pp.69-126). Center for Addiction and Mental Health, Toronto.

Harlow, C. W. (1999). Bureau of Justice Statistics Selected Findings. (Report No. NCJ 172879). Washington, DC.

Hernandez, J. (1992). Substance abuse among sexually abused adolescents and their family. Journal of Adolescent Health, 13, 658-662.

Holmes, W. C. (1997). Association between a history of childhood sexual abuse and subsequent, adolescent psychoactive substance use disorder in a sample of HIV seropositive men. Society for Adolescent Medicine, 20, 414-419.

Horn, J. L. (1965). A rationale and test for the number of factors in factor analysis. Psychometrika, 30(2), 179 - 185. 
Isohanni, M., Moilanen, I., \& Rantakallio, P. (1991). Determinants of teenage smoking, with special reference to non-standard family background. British Journal of Addiction, 86, 391-398.

Izzo, R. L., \& Ross, R. R. (1990). Meta-analysis of rehabilitative programs for juvenile delinquents: A brief report. Criminal Justice and Behavior, 17(1), 134142.

Janchill, N., Hawkes, J., \& Messina, M. (2005). Post-treatment outcomes among adjudicated adolescent males and females in modified therapeutic community treatment. Substance Use and Misuse, 40(7), 975-996.

Johnson, R. J., Ross, M. W., Taylor, W. C., Williams, M. L., Carvajal, R. I., \& Peters, R. J. (2005). A history of drug use and childhood sexual abuse among incarcerated males in a county jail. Substance Use \& Misuse, 40, 211-229.

Johnston, L. D., Bachman, J. G., O'Malley, P. M., \& Schulenberg, J. E. (2001). Monitoring the future a continuing study of American youth. Ann Arbor, MI.: University of Michigan, Institute for Social Research, Survey Research Center.

Johnston, L. D., O'Malley, P. M., \& Bachman, J. G. (2003). Monitoring the Future national survey results on adolescent drug use: Overview of key findings, 2002 (NIH Publication No. 03-5374). Bethesda, MD: National. Institute on Drug Abuse.

Kaplan, H. B., Martin, S. S., \& Robbins, C. (1986). Pathways to adolescent drug use: Self-degradation, peer influences, weakening social controls, and early substance use. Journal of Health and Social Behavior, 25, 270-289.

Kendler, K. S., Bulik, C. M., Silberg, J., Hettema, J. M., Myers, J., \& Prescott, C. A. (2000). Childhood sexual abuse and adult psychiatric and substance use disorders in women. Archives of General Psychiatry, 57(10), 953-959.

Khantzian, E. J. (1997). The self-medication hypothesis of substance use disorders: A reconsideration and recent application. Harvard Review of Psychiatry, 4(5), 231244.

Kranzler, H. R., Kadden, R. M., \& Babor, T. F. (1996). Validity of the SCID in substance abuse patients. Addiction 91 (6), 859-868.

Lebeau-Craven, R., Stein, L. A. R., Barnett, N., Colby, S., Smith, J, \& Canto, A. (2003). Prevalence of alcohol and drug use among youth in a Rhode Island training facility. Substance Use \& Misuse, 38, 825-834. 
Lipton, D. S. (1996). Prison-based therapeutic communities: Their success with drug-abusing offenders. National Institute of Justice Journal, 12-22.

Loeber, R., Stouthamer-Loeber, M., \& White, H. R. (1999). Developmental aspects of delinquency and internalizing problems and their association with persistent juvenile substance use between ages 7 and 18. Journal of Clinical Child Psychology, 28(3), 322-332.

LuCuyer, E. A. (1992). Milieu therapy for short stay units: A transformed practice theory. Archives of Psychiatric Nursing, 6(2), 108-116.

Marlatt, G. A., \& Gordon, J. (1980). Determinants of relapse: Implications for the maintenance of behavior change. In P. O. Davidson \& S. M. Davidson (Eds.), Behavioral Medicine (pp. 410-452). New York: Brunner/Mazel.

Martinson, R. (1974). What works? Questions and answers about prison reform. Prison Reform, 35, 22-54.

McManus, M., Alessi, N. E., Grapentine, W. L., \& Brickman, A. (1984). Psychiatric disturbance in serious delinquents. Journal of the American Academy of Child Psychiatry, 23, 602-625.

Miller, W. R. (1995). Increasing motivation for change. In R. K. Hester \& W. R. Miller (Eds.), Handbook of alcoholism treatment approaches ( $2^{\text {nd }}$ ed., pp. 89-104). Boston: Allyn \& Bacon.

Mueser, K. T., Drake, R. E., \& Wallach, M. A. (1998). Dual diagnosis: A review of etiological theories. Addictive Behaviors, 23(6), 717-734.

Mulrow, C. D., Williams, J. W., Gerety, M. B., et al. (1995) Case- finding instruments for depression in primary care settings. Annals of Internal Medicine, 122, 913-921.

National Institute of Justice, Arrestee drug abuse monitoring (ADAM; 1999). ADAM Annual Report (NIJ 193013). Washington, DC: Abt Associates Inc.

O'Callahan, F. V., \& Hannon, T. (2003). Normalization of marijuana use: It's effects on adolescents' intentions to use marijuana. Substance Use \& Misuse, 38(2), 185-199.

Office of Applied Studies, Substance Abuse and Mental Health Services Administration. (2001). Summary of findings from the 2000 National Household Survey on Drug Abuse (DHHS Publication No. SMA 01-3549, NHSDA Series H-13). Rockville, MD: Substance Abuse and Mental Health Services Administration, Office of Applied Studies. 
Orlando, M., Chan, K. S., \& Morral, A. R. (2003). Retention of court-ordered youths in residential treatment programs: Client characteristics and treatment process effects. American Journal of Drug and Alcohol Abuse, 29(2), 337-357.

Parks, G. A., \& Marlatt, G. A. (1999). Keeping "what works" working: Cognitive behavioral relapse prevention therapy with substance abusing offenders. In Latessa (Ed.), Strategic solutions: The International Community Corrections Association examines substance abuse. Washington, DC: American Correctional Association.

Pearson, F. S., \& Lipton, D. S. (1999). A meta-analytic review of the effectiveness of corrections-based treatments for drug abuse. The Prison Journal, 79(4), 384410.

Radloff, L. S. (1977). The CES-D scale: A self report depression scale for research in the general population. Applied Psychological Measurement,1, $385-401$.

Rhodes, J. E., \& Fischer, K. (1993). Spanning the gender gap: Gender differences in delinquency among inner-city adolescents. Adolescence, 28(112), 879-890.

Rob, M., Reynolds, I., \& Finlayson, P. F. (1990). Adolescent marijuana use: Risk factors and implications. Australian and New Zealand Journal of Psychiatry, $24,47-56$.

Rosenheck, R., \& Seibyl, C. L. (1998). Participation and outcome in a residential treatment and work therapy program for addictive disorders: The effects of race. American Journal of Psychiatry, 155(8), 1029-1034.

Schafer, J., \& Brown, S. A. (1991). Marijuana and cocaine effects expectancies and drug use patterns. Journal of Consulting and Clinical Psychology, 59(4), $558-565$.

Schulberg, H. C., McClelland, S. M., Ganguli, M., Christy, W., \& Frank ,R. (1985). Assessing depression in primary medical and psychiatric practices. Archives of General Psychiatry, 42, 1164-1170.

Simpson, T. L., \& Miller, W. R. (2002). Concomitance between childhood sexual and physical abuse and substance use problems: A review. Clinical Psychology Review, 22, 27-77.

Skyre, I., Onstad, S., Torgersen, S., \& Kringlen, E. (1991). High interrater reliability for the Structured Clinical Interview for DSM-III-R Axis I (SCID-I). Acta Psychiatrica Scandanavia, 84(2), 167-173. 
Sobell, L. C., Maisto, S. A., Sobell, M. B., \& Cooper, A. M. (1979). Reliability of alcohol abusers' self-reports of drinking behavior. Behavior Research and Therapy, 17, 157-160.

Sobell, M. B., Sobell, L. C., Klajner, F. P., \& Pavan, D. (1986). The reliability of a timeline method for assessing normal drinker college students' recent drinking history: Utility for alcohol research. Addictive Behaviors, 11 (2), 149-161.

Sobell, L. C., Sobell, M. B., Leo, G. I., \& Cancilla, A. (1988). Reliability of a timeline method: Assessing normal drinkers' reports of recent drinking and a comparative evaluation across several populations. British Journal of Addictions, 83(4), 393-402.

Spitzer, R. L., Williams, J. B., Gibbon, M., \& First, M. B. (1990). Structured Clinical Interview for DSM-III-R, Patient Edition/Non-patient Edition (SCIDP/SCID-NP), Washington, D.C.: American Psychiatric Press, Inc.

Stein, L. A. R., Colby, S. M., Barnett, N. P., Monti, P. M., Golembeski, C., LebeauCraven, R., \& Miranda, R. (2006). Enhancing substance abuse treatment engagement in incarcerated adolescents. Psychological Services, 3(1), 25-34.

Stephens, R. S., Wertz, J. S., \& Roffman, R. A. (2004). Predictors of marijuana treatment outcomes: The role of self-efficacy. Journal of Substance Abuse, 5(4), 341-354.

Stoker, A., \& Swadi, H. (1990). Perceived family relationships in drug abusing adolescents. Drug and Alcohol Dependence, 25, 293-297.

Storvoll, E. E., Wichstrom, L., \& Pape, H. (2003). Gender differences in the association between conduct problems and other problems among adolescents. Journal of Scandinavian Studies in Criminology and Crime Prevention, 3, 194-209.

Substance Abuse and Mental Health Services Administration. Office of Applied Sciences. Preliminary Results from the 2001 National Household Survey on Drug Abuse. DHHS No. (SMA) 02-3759. Rockville, MD: SAMHSA, 2002.

Substance Abuse and Mental Health Services Administration. Center for Substance abuse Treatment. Treatment Improvement Protocol (TIP) Series, 39.

Swadi, H. (1992). Relative risk factors in detecting adolescent drug abuse. Drug and Alcohol Dependence, 31, 77-83.

Swadi, H. (1994). Parenting capacity and substance misuse: An assessment scheme. ACPP Rev. Newsletter 16, 237-244.

Swadi, H. (1999). Individual risk factors for substance use. Drug and Alcohol Dependence, 55, 209-224. 
Tabachnick, B. G., \& Fidell, L. S. (2001). Using multivariate statistics, Allyn and Bacon, 4th ed.

Thornberry, T. P., Tolnay, S. E., Flanagan. T. J., \& Glynn, P. (1991). Children in custody 1987: A comparison of public and private juvenile custody facilities. Washington, D.C.: U.S. Department of Justice. Office of Juvenile Justice and Delinquency Prevention.

Torrealday, O., Stein, L. A. R., Colby, S. M., Barnett, N. P., Monti, P. M., Golembeske, C., \& Lebeau-Craven, R. Validity of a Brief Marijuana Effects Expectancy Questionnaire for Adolescents: MEEQ-B. Manuscript in press, Brown University.

Webb, C., Burleson, J., \& Ungemack, J. A. (2002). Treating juvenile offenders for marijuana problems. Addiction, 97 (Suppl 1), 35-45.

Webster-Stratton, C. (1996). Early-Onset conduct problems: Does gender make a difference. Journal of Consulting and Clinical Psychology, 64(3), 540-551.

Weid, V. D., \& Lutova, N. B. (2002). Specific effects of G. Ammon's milieu therapy. International Journal of Mental Health, 31(2), 18-22.

Williams, J. B. W., Gibbon, M., First, M. B., Spitzer, R. L., Davis, M., Borus, J., Howes, M. J., Kane, J., Pope, H. G., Rounsaville, B., \& Wittchen, H. (1992). The structured clinical interview for DSM-III-R (SCID) II: Multi-site test-retest Reliability, Archives of General Psychiatry, 49(8), 630-636.

Wills, T., \& Cleary, S. (1996). How are social support effects mediated? A test with parental support and adolescent substance use. Journal of Personality and Social Psychology, 6, 1-20.

Wood, J., Foy, D.W., Layne, C., Pynoos, R., \& James, C. B. (2002). An examination of the relationships between violence exposure, posttraumatic stress symptomotology, and delinquent activity: An "Ethopathological" model of delinquent behavior among incarcerated adolescents. In R. Greenwald (Ed.), Trauma and Juvenile Delinquency, Theory, Research, and Interventions, (pp.127-148). New York, NY: Hawthorn Press.

Zanarini, M. C., \& Frankenburg, F. R. (2001). Attainment and maintenance of reliability of axis I and axis II disorders over the course of a longitudinal study. Comprehensive Psychology, 42(5), 369-374.

Zwick, W. R., \& Velicer, W. F. (1986). Comparison of five rules for determining the number of components to retain. Psychological Bulletin, 99, 432-442. 